\title{
La solidaridad como fuente de deberes. Elementos para su incardinación en el sistema jurídico-penal ${ }^{*}$
}

Solidarity as a source of duties. Elements for its allocation in the criminal-legal system

\author{
Juan Ignacio Piña Rochefort \\ Profesor de Derecho Penal \\ Pontificia Universidad Católica de Chile \\ jipina@uc.cl
}

\section{Resumen}

El presente artículo intenta ofrecer una sistematización de los usualmente llamados "deberes de solidaridad", proponiendo una forma de integración en el sistema general de deberes cuya infracción puede justificar una sanción penal. Para ello se ofrece una sucinta revisión histórica del rol que ha desempeñado la solidaridad como estructura de cohesión social desde el surgimiento de las primeras comunidades humanas hasta alcanzar su relativamente marginal posición actual en la sociedad funcionalmente diferenciada. Especial mención se hace a la forma en que el Derecho la ha reconocido en distintas instituciones jurídicas. Asimismo, se ofrece una propuesta para explicar el alcance de los deberes generales de solidaridad y la legitimidad de su conminación con una pena en un Derecho penal liberal.

Palabras clave: Solidaridad, Deberes positivos, Deberes negativos, Deberes generales, deberes especiales.

\begin{abstract}
:
This paper seeks to offer a systematized approach towards the so-called "duties of solidarity", proposing a form of integration between them and the general regime of duties the violation of which could potentially lead to criminal liability. To that effect, the paper includes a brief historical discussion of the role that has been assigned to solidarity, as a structure geared towards social cohesion, since the emergence of the first human communities, until they reach their current relatively marginal situation vis-à-vis functionally differentiated society. The paper contains a specific discussion on how the Law has recognized these duties of solidarity throughout various legal institutions. Likewise, it posits a proposal to explain the scope of the general duties of solidarity and the legitimacy of punishment through a penalty under liberal criminal law.
\end{abstract}

Keywords: Solidarity, positive duties, negative duties, general duties, special duties.

\footnotetext{
${ }^{*}$ El presente trabajo se ha desarrollado en el marco del Proyecto Fondecyt Regular número 1150264.
} 


\section{PIÑA, Juan Ignacio, "La solidaridad como fuente de deberes. Elementos para su incardinación en el sistema jurídico penal”.}

\section{Introducción}

La igualdad natural es el fundamento de la obligación de amarse mutuamente, sobre la cual basa los deberes que tenemos para con los otros John Locke, Segundo Tratado del Gobierno Civil (Cap. II)

Los deberes positivos que tienen como fundamento la solidaridad entre los ciudadanos no parecen haber encontrado su acomodo en la teoría del Derecho. Si bien desde la teoría política la noción de solidaridad —entendida en el sentido clásico de la prestación de una contribución al otro o a la comunidad - cuenta con un reconocimiento que permite fundamentar una serie de instituciones, en el sistema jurídico no parece sino mostrarse en apenas una serie de episodios aislados y marginales. En el ámbito del Derecho penal lo anterior cobra especial visibilidad. ${ }^{1}$ La conminación con penas de la infracción de deberes de solidaridad parece llevar al límite las obligaciones ciudadanas difuminando peligrosamente la frontera entre el Derecho y la Moral. En otros términos, se aparecen dichos episodios como una peligrosa transformación en obligaciones jurídicamente exigibles de acciones que en realidad son supererogatorias, lo que transformaría los actos "buenos" en "exigibles", 2 exponiendo al sistema jurídico a un peligroso integrismo con el sistema moral y amenazando la autonomía individual. ${ }^{3}$

Entendido de esta forma, no parece infundado el temor que produce dar a los deberes de solidaridad un reconocimiento apenas más que marginal. La diferenciación del sistema jurídico del sistema moral ha sido un proceso progresivo y paulatino que ha mostrado relevantes rendimientos en la evolución social y la aspiración a profundizarlo en una

\footnotetext{
${ }^{1}$ Vid., entre otros, ALCÁCER GUIRAO, Rafael, "Autonomía, solidaridad y deber de socorro (Un apunte histórico)", ADPCP LIII (2000), pp. 361-411; RAGUES I VALLÉS, Ramón, "Proceso al buen samaritano. Acciones de salvamento y responsabilidad por daños", Indret 2/2001 (2001), pp. 1-12 en: http://www.indret.com/pdf/049 es.pdf [visitado el 23/11/18]; PAWLIK, Michael, Das Unrecht des Bürgers, Grundlinien der Allgemeiner Verbrechenslehre, Tübingen: Mohr Siebeck, 2012; VAN WEEZEL, Alex, "Necesidad justificante y solidaridad", en: CÁRDENAS, Claudia; FERDMAN, Jorge (Coords.), El Derecho penal como teoría y como práctica. Libro en homenaje a Alfredo Etcheberry Orthusteguy, Santiago: Thomson Reuters, 2016, pp. 213-230; VALENZUELA, Jonatan, "La narrativa del deber de ayudar a otro", Ius et Praxis n 2 (2014), pp. 555-574; ROBLES PLANAS, Ricardo, "Deberes negativos y positivos en Derecho penal”, Indret, 4/2013 (2013), pp. 1-21 en: http://www.indret.com/pdf/1008.pdf [visitado el 23/11/18]; VARONA GÓMEZ, Daniel, Derecho penal y solidaridad. Teoría y práctica del mandato penal de socorro, Madrid: Dykinson, 2005; MORGENSTERN, Henrike, Unterlassene Hilfeleistung, Solidarität und Recht, Frankfurt a.M.: Peter Lang, 1997, p. 125; CADOPPI, Alberto, "Failure to rescue and the continental criminal law", en: MENLOWE, Michael; MCCALL, Alexander (eds.), The duty to rescue. The jurisprudence of aid, Aldershot: Darmouth, 1993.

${ }^{2}$ Probablemente una de las afirmaciones más tajantes respecto de que los deberes negativos son asunto del Derecho y el Estado y que los positivos o de auxilio son sólo asunto de la Moral puede encontrarse en SCHOPENHAUER, Arthur, Preisschrift über die Grundlage der Moral, (ed. Hans Ebeling) Hamburgo: Meiner, 1979, p. 115. Vid. VAN WEEZEL, Alex, "Solidaridad en el tráfico motorizado. El delito de omisión de auxilio en caso de accidentes", Doctrina y Jurisprudencia penal, ed. Especial (2014), pp. 191-204, p. 196.

${ }^{3}$ Naturalmente, esta afirmación pende del alcance que se de a la noción autonomía, pues un concepto amplio como el que propone RAZ, Joseph, The Morality of freedom, Oxford University Press, 1986, p. 416 no ve inconvenientes en que el Estado imponga deberes de mejoramiento de la posición de terceros. Vid, además, ASHWORTH, Andrew, Positive obligations in criminal law, Oxford: Hart Publishing, 2015, p. 35.
} 
sociedad de libertades parece un imperativo. ${ }^{4}$ En este sentido, deslindar adecuadamente aquellos asuntos que son propios del Derecho y eventualmente acreedores de sanciones que sólo merecen un reproche moral resulta una preocupación atendible. Lo que resta por dilucidar, sin embargo, es si la intuición de que la solidaridad se identifica más con conductas supererogatorias es correcta o si existen razones para sostener que la función social que desempeña pueda generar imperativos de conducta $y$, en consecuencia, transformarla plenamente en un asunto del Derecho.

En el ámbito propio del sistema jurídico penal, una descripción general de nuestras estructuras de imputación pareciera mostrar un sistema que descansa fundamentalmente en la distinción de dos tipos de deberes susceptibles de infringirse, y cuya infracción se encuentra conminada penalmente: la infracción del deber general negativo de no dañar y la infracción de los deberes especiales asociados a una determinada posición. ${ }^{5}$ No cabe ninguna duda que estos dos son los que han arrastrado las mayores preocupaciones del Derecho penal. Sin embargo, si se aspirara a acometer un análisis completo de nuestro sistema de imputación de responsabilidad, es poco probable que, prima facie, las formas de responsabilidad por dañar a otros (infracción del principio neminem laedere) o por infringir deberes institucionales que pesan sobre quien ocupa una determinada posición en el entramado de las relaciones sociales, lograsen subsumir aquellos casos en que se infringen deberes de asistencia a terceros con los que el agente no se encuentra especialmente vinculado. A estos últimos casos se los suele entender como la infracción de deberes de solidaridad. ${ }^{6}$

De este modo, figuras como la omisión de socorro, ${ }^{7}$ el abandono de niños, ${ }^{8}$ la denegación de asistencia a la autoridad ${ }^{9}$ o incluso la infracción de los deberes de tolerancia emanados

\footnotetext{
${ }^{4}$ Sobre esto largamente LUHMANN, Niklas, Ausidfferenzierung des Rechts. Beiträge sur Rechtstheorie und Rechtssoziologie, Frankfurt a.M.: Suhrkamp, 1995, pássim; EL MISMO, La moral de la sociedad, Trads. ORTEGA "et al", Madrid: Trotta, 2013, p. 128 y ss. Vid. también, PIÑA ROCHEFORT, Juan Ignacio, Derecho penal, Fundamentos de la Responsabilidad. $2^{a}$ ed., Santiago: Thompson Reuters, 2014, p. 22 y ss.

${ }^{5}$ Sobre esto nos hemos detenido largamente en PIÑA ROCHEFORT, Derecho penal, Fundamentos de la Responsabilidad, cit. nota $\mathrm{n}^{\circ} 4$, p. 141 y ss.

${ }^{6} \mathrm{Si}$ bien generalmente se asocian a omisiones de socorro no pueden — como veremos - limitarse en caso alguno solamente a éstos. Formas análogas de responsabilidad por infracción de deberes de auxilio pueden encontrarse en el Derecho español (art. 195 CP), alemán (§ 323c StGB), italiano (art. 593 CP), francés (art. 226 CP). La tendencia contraria puede apreciarse en el ámbito jurídico del Common Law. Vid. la interesante comparación de ambos sistemas en AGULNIK, Peter; RIVKIN, Heidi, "Criminal Liability for failure to rescue: a brief survey of french and american law", Touro International Law Review, $\mathrm{n}^{\circ} 8$ (1998) disponible en http://www.agulnicklaw.com/articles/duty.html [visitado el 23/11/18]; ASHWORTH, Positive Obligations in criminal law, cit. nota $\mathrm{n}^{\circ}$ 3, pp. 31-80 con un reconocimiento excepcional pero muy valioso. Vid. También RADCLIFFE, James (Ed.), The good samaritan and the law, Nueva York: Anchor Books, 1966 (reimpr. 1980); RAGUES I VALLÉS, Ramón, "Proceso al buen samaritano", cit. nota nº 1.

${ }^{7}$ Art. 494 número 14 del CP. Sobre el origen histórico vid. el sorprendente trabajo de ALCÁCER GUIRAO, Rafael, "Autonomía, solidaridad y deber de socorro", cit. nota n 1, p. 361-411.

${ }^{8}$ Art. 494 número 13 del CP.

${ }^{9}$ Art. 496 número 2 del CP. Revisando el origen de este deber en el $\S 360$ del StGB de 1871, ALCÁCER GUIRAO, Rafael, “Autonomía, solidaridad y deber de socorro", cit. nota no 1, p. 399 y ss.; RENZIKOWSKI, Joachim, "Solidarität in Notsituationen. ein historischer Überblick von Thomas v. Aquin bis Hegel”, en: VON HIRSCH, Andreas, NEUMANN, Ulfrid; SEELMANN, Kurt (Eds.), Solidarität im Strafrecht, Baden Baden: Nomos, 2013, pp. 13- 35.
} 


\section{PIÑA, Juan Ignacio, "La solidaridad como fuente de deberes. Elementos para su incardinación en el sistema jurídico penal”.}

del estado de necesidad agresivo, ${ }^{10}$ no parecen acomodarse ni en responsabilidad por organización (pues no se está organizando defectuosamente el ámbito propio causando daño, sino que no se está configurando para auxiliar a terceros) ni en responsabilidad institucional (pues no hay vinculación institucional alguna entre el omitente y la "víctima").

Por el contrario, detrás de estas incriminaciones (o infracciones) hay deberes generales de auxilio a terceros extraños o a la comunidad toda que fuerzan a modificar la propia organización, que en una sociedad de libertades ya se había lícitamente configurado de otro modo. En otros términos, parece que el ordenamiento jurídico dijera: "organice su propio ámbito como quiera, pero sepa que en ciertas ocasiones deberá modificar esa organización para asistir a otros". Ello naturalmente podría conducir a la afirmación de que infracciones a ese deber constituirían una tercera forma de responsabilidad, diferente de las anteriores. Sin embargo, esto es precisamente lo que debería someterse a revisión.

Las siguientes consideraciones pretenden ofrecer una sencilla taxonomía de los deberes solidarísticos y su incardinación en el conjunto de deberes cuya infracción es susceptible de sanción penal, así como ofrecer algunos elementos que contribuyan a la discusión respecto de si la solidaridad puede generar legítimamente imperativos de conducta conminados penalmente y que el entendimiento tradicional -que exige someterla a una estricta excepcionalidad - debe desafiarse.

\section{Deberes de solidaridad y evolución social}

Toda sociedad implica solidaridad; toda regla de conducta que toca a los hombres que viven en sociedad ordena cooperar con dicha solidaridad.

León Duguit, Tratado de Derecho Constitucional.

\subsection{Generalidades}

Es poco probable que pueda comprenderse la posición que tienen los deberes de solidaridad recogidos en nuestros ordenamientos de raigambre germánico continental sin observarlos a la luz del devenir de su ubicación en la evolución social. Los espacios otorgados a la solidaridad desde etapas que podrían denominarse pre-sociales (o protosociales) han variado a lo largo del tiempo tanto en su relevancia como en su cuantía. En efecto, es evidente que en las etapas previas a la estructuración social, la forma de articular las relaciones entre los miembros del cuerpo social estaba marcada por un sentimiento de pertenencia común ${ }^{12}$ que dotaba — por decirlo de algún modo— de absoluta naturalidad a la

\footnotetext{
${ }^{10}$ Sobre esto vid., con referencias, SILVA SÁNCHEZ, Jesús-María, "Derechos de necesidad agresiva y deberes del tolerancia", en: VV.AA. Homenaje al Prof. Rodríguez Mourullo, Madrid: Thompson/Civitas, 2005 [disponible también en versión electrónica en: http://www.cervantesvirtual.com/obra/derechos-denecesidad-agresiva-y-deberes-de-tolerancia-0/], p. 9 y ss.

11 Respecto de la relación entre esta forma de responsabilidad y el Derecho de daños vid. RAGUES I VALLÉS, "Proceso al buen samaritano", cit. nota n 6, pássim.

${ }^{12}$ WEBER, Max, Conceptos sociológicos fundamentales, Madrid: Alianza, 2006, p. 146.
} 
relación solidarística. Esta comunidad ${ }^{13}$ se caracterizaba por un agrupamiento relativamente natural y espontáneo y que originariamente encontraba su conciencia de unidad y pertenencia en las relaciones de parentesco que les daban origen (apareamiento, maternidad, paternidad, fraternidad) pero que en caso alguno se limitó exclusivamente a ello. En estos pequeños grupos los vínculos solidarios (y por ende los deberes asociados a ellos) resultaban difícilmente distinguibles de otras formas de deber, básicamente por dos razones. Por una parte, porque al estructurarse estos grupos sobre la base de relaciones sanguíneas resultaba muy difícil distinguir esta solidaridad de otras formas de deber positivo que hoy tendemos a identificar como institucionales (como la relación paterno filial, el matrimonio, etc.). Por otro lado, la coexistencia de estos deberes positivos con los deberes negativos de no dañar a otros, hacía ardua su distinción en una etapa en que las condiciones de subsistencia de la comunidad todavía eran precarias y el deber de auxilio resultaba tan relevante para la subsistencia individual como el neminem laedere. En otros términos, cuando una comunidad se enfrenta a un entorno hostil que la amenaza - casi al modo de lo que hoy entenderíamos como una comunidad de riesgo-, la infracción de un deber de solidaridad vinculado a la subsistencia tiene un disvalor prácticamente indistinguible del propio deber negativo de no dañar a otros. ${ }^{14}$ Este es un punto altamente relevante pues originariamente, en el estado comunitario pre-social, el deber solidarístico dentro de la comunidad es tan originario, tan estructurante en lo que respecta a las condiciones de subsistencia del grupo social, como el propio deber negativo de no dañar.

Sin embargo, esta primera forma de solidaridad naturalmente difiere $-\mathrm{y}$ no sólo por su marginalización — de la que podría reconocerse en nuestros días. Ya esta asunción permite trazar algunas distinciones entre los albores de la solidaridad comunitaria y aquella que sería propia de la sociedad moderna. ${ }^{15}$

\subsection{La Solidaridad comunitaria: semejanza y pertenencia}

\footnotetext{
${ }^{13}$ Epigonal en la distinción entre comunidad (Gemeinschaft) y sociedad (Gesellschaft), TÖNNIES, Ferdinand, Comunidad y Asociación, Granada: Comares, 2009, pássim (después resumida y actualizada en el opúsculo Gemeinschaft und Gessellschaft, publicado en el Handwörterbuch der Soziologie, editado por Vierkandt en 1931). Vid. respecto de los desarrollos posteriores de la distinción, KÖNIG, René, "Die Begriffe Gemeinschaft und Gesellschaft bei Ferdinand Tönnies”, Kölner Zeitschrift für Soziologie und Sozialpsychologie 7, $\mathrm{n}^{\circ} 3$ (1955), pp. 348-420. Tanto para Tönnies como para Weber, la comunidad aparece más bien como una forma tipológica y no necesariamente como una sustancia. De ahí que su principal valor sea más bien metodológico. Vid. TÖNNIES, Ferdinand, Sociología, México: FCE, 1946, p. 100-111 y MONEREO PÉREZ, en su Estudio Preliminar a Comunidad y asociación, Granada: Comares, 2009, p. XIX. Luego, sólo en cierta medida pueden entenderse como "épocas históricas". En cierto sentido, la distinción también aparece en POPPER, Karl, La sociedad abierta y sus enemigos, Trad. LOEDEL, Buenos Aires: Paidos, 1967, quien distingue entre las sociedades holistas y las sociedades cerradas.

${ }^{14}$ Esto puede intuirse claramente en DURKHEIM, Emile, De la división del trabajo social, Trad. POSADA, Madrid: Akal, 2001, p. 94 y ss. Pero en caso alguno sólo en él. Resulta muy interesante, y volveremos sobre esto, que Mill, naturalmente pensando en sociedades (y no ya en comunidades) lo haya visto igualmente claro en Sobre la Libertad, p. 55.

${ }^{15}$ Hacen esta distinción PECES-BARBA MARTÍNEZ, Gregorio, Curso de Derechos Fundamentales I (Teoría General), Madrid: Eudema, 1991, p. 222; FERNÁNDEZ SEGADO, "La solidaridad como principio constitucional ”, Teoría y Realidad Constitucional (UNED), n³0 (2012), pp. 139-181, p. 142 y ss.
} 


\section{PIÑA, Juan Ignacio, "La solidaridad como fuente de deberes. Elementos para su incardinación en el sistema jurídico penal”.}

Que la solidaridad es la base de la organización comunitaria originaria es prácticamente un lugar común en el análisis sociológico evolutivo. ${ }^{16}$ La propia etimología de la solidaridad - esto es la raíz latina solidum como uno, compacto- da cuenta de que la estructura misma de la comunidad o communitas (común-unidad) descansa en la integración o pertenencia a un grupo. ${ }^{17}$

El vínculo fundamental sobre el que se estructura dicha pertenencia es inicialmente el parentesco consanguíneo y luego un parentesco por afinidad que a lo largo de la evolución irá relajando su estrechez inicial. ${ }^{18}$ Esto permite la progresiva incorporación al clan de otras familias que se vinculan por individuos afines o consanguíneos comunes. La solidaridad que funda estas comunidades es una especie de solidaridad natural, mecánica y absolutamente inevitable, ${ }^{19}$ sin perjuicio que también dentro de ella pueden encontrarse ciertas formas de estructuración institucional. ${ }^{20}$ Adicionalmente, en esta etapa, la subsistencia del grupo exige una fuerte relación de asistencia recíproca y por ello resulta casi imposible distinguir como fuente de la solidaridad esa pertenencia familiar (en sentido extendido) o la necesidad de subsistencia. El entorno adverso y cargado de riesgos se

\footnotetext{
${ }^{16}$ WEBER, Conceptos sociológicos fundamentales, cit. nota ${ }^{\circ} 12$, p. 161 y ss.; TÖNNIES, Comunidad y asociación, cit. nota $\mathrm{n}^{\circ} 13$, p. 9 y ss.; DURKHEIM, De la división del trabajo social, cit. nota $\mathrm{n}^{\circ} 14$, p. 93 y ss., 123.
}

${ }^{17}$ WEBER, Conceptos sociológicos fundamentales, cit. nota $\mathrm{n}^{\circ} 12$, p.146 y ss., dirá "llamamos comunidad a una relación social en la medida que la acción social esté basada en el sentimiento subjetivo de pertenencia en común". Este concepto permite la coexistencia de comunidades en el seno de sociedades en que este sentimiento de pertenencia común ya no sea el eje de estructuración de las relaciones de los individuos. HOELZL, Michael, "Recognizing the sacrificial victim. The problem of solidarity for critical social theory", Journal for Cultural and Religious theory, 6/1 (2004), pp.45-64, p. 46.

${ }^{18}$ El germen de la comunidad — dirá TÖNNIES, Comunidad y asociación, cit. nota no 13 , p.9-, se encuentra en la unidad de voluntades por estrecha interrelación (padres, cónyuges, hermanos). La unidad básica de estas sociedades antiguas, dirá MAINE, H.J.S., Ancient Law, Its connection with the early History of society and its relation to modern ideas, Londres: John Murray, 1939, p. 103 y 106 y ss. es la familia y no el individuo y la única base de la comunidad es el parentesco de sangre, real o ficticio. En la misma línea MORGAN, Lewis, Ancient society on researches in the lines of human progress from savagery trough barbarism to civilization, Nueva York: H. Holt and Company, 1877, p. 79 al hacer notar que esta primera forma de civilización sobre personas y relaciones puramente personales en que la gens es la unidad mínima. Esta última dará lugar posteriormente a partir de unión con otras a fratrías y luego a tribus. Vid., la preciosa descripción que hace Herbert SPENCER en su clásica La ciencia social. Fundamentos de la sociología (3 ${ }^{\mathrm{a}}$ ed.), Madrid: Np, 1886, p. 103 y ss. Vid. también REDFIELD, Robert, The Little community. Peasant Society and Culture, Chicago/Londres: University of Chicago Press, 1960. Sobre esto además, LLINARES GARCÍA, Mar, "La búsqueda de los principios de organización de la sociedad”, Gazeta de Antropología n¹3 (1997), pp. 1-11, p. $2-4$.

${ }^{19}$ Sobre esto, DURKHEIM, De la división del trabajo social, cit. nota no 14 , pássim.

20 Estudios etnológicos muestran que la adscripción de deberes positivos dentro de las relaciones de parentesco también dan cuenta de formas de institucionalización. En otros términos, dentro de las relaciones de parentesco, también es posible identificar posiciones institucionales que dan preeminencia a ciertos parientes por sobre otros. Algunas relaciones diferenciadas entre tíos y sobrinos maternos y las obligaciones recíprocas en algunas tribus balinesas o africanas dan cuenta de ello Sobre esto MEAD, Margaret, Sex and temperament in three primitive societies, Nueva York: W. Morrow \& Co, 1935, pp 176-185. Además, WILLIAMS, F.E., Natives of lake Kutubu, Papua, Oceania, Vol. XI, 1940-1941 y XII, 1941-1942, p. 265280 del Vol. XI; o Dubois de Monpereux (1839), ambos citados en PÁEZ DÍAZ DE LEÓN, Laura (ed.), Vertientes contemporáneas del pensamiento social francés, México: UNAM, 2002, p. 218-219. 
trasforman en un elemento cohesionador. ${ }^{21}$ Ambos elementos (pertenencia y riesgo) se encuentran en esta etapa profundamente amalgamados.

Sin embargo, la incorporación de sujetos no vinculados por sangre o afinidad sino por necesidad de cooperación y coordinación hacia un fin común (que inicialmente no es más que la supervivencia) lleva a esta precaria organización a otro estadio. ${ }^{22}$ Esta es una cuestión crítica, pues cuando el fin común es la supervivencia, es decir la mantención de las condiciones de subsistencia del grupo, la situación es analogable a la de una comunidad de riesgos. En otros términos, un entorno adverso es un entorno que sólo puede enfrentarse de un modo solidum (compacto, firme, uno) y el papel que juega la solidaridad — la etimología en caso alguno es arbitraria - en ello es absolutamente fundamental. Estos estadios han sido también caracterizados como sociedades o asociaciones mecánicas, y descansan precisamente en una solidaridad mecánica (Durkheim). La sociedad mecánica hace descansar la solidaridad en la conciencia colectiva, en el conjunto de las creencias y sentimientos colectivos de los miembros. ${ }^{23}$ Por eso esta comunidad también descansa en la noción de semejanza (todo lo contrario a las sociedades más evolucionadas en que la "diferencia" se entroniza como cuestión fundamental) pues los miembros se encuentran atraídos porque se parecen y porque están ligados a lo que constituye la condición de existencia de ese tipo colectivo ${ }^{24}$ : la comunidad se cimenta en la confianza y ésta descansa en la familiaridad y semejanza. ${ }^{25}$

La incorporación de terceros que ya no pueden vincularse por parentesco sino por la unión de voluntades - lo que TÖNNIES llama "comunidades de espíritu"26 - que entrañan coordinación hacia una meta común produce un salto cuántico en las relaciones comunitarias. En este punto la comunidad estructurada inicialmente por los vínculos de sangre se cohesiona por la disposición de sus integrantes de formar parte del grupo teniendo como primera razón para ello la necesidad de subsistencia. Probablemente sea este el momento cuando por primera vez aparece la solidaridad en sentido estricto como propiedad emergente de un determinado estadio de complejidad social. ${ }^{27}$ Durante la etapa en que es la relación de parentesco la que estructura la comunidad, la solidaridad no puede distinguirse de la asistencia indefectiblemente debida entre los integrantes, ${ }^{28}$ y por eso Durkheim la llamaría "fraternidad natural". ${ }^{29}$ Sin embargo, cuando ya no es el parentesco natural sino la

\footnotetext{
${ }^{21}$ Ello no es sino la expresión social de la comunión del instinto de autoconservación de los integrantes.

${ }^{22}$ Se trata aquí de estadios metodológicos (tipológicos) y sólo parcialmente históricos. Así también en Weber y Tönnies. Vid. MONEREO PÉREZ, Estudio Preliminar a Tönnies, Comunidad y asociación, cit. nota $\mathrm{n}^{\circ} 13$, p. XIX.

${ }^{23}$ DURKHEIM, De la división del trabajo social, cit. nota ${ }^{\circ} 14$, p. 94 y ss.

${ }^{24}$ DURKHEIM, De la división del trabajo social, cit. nota $\mathrm{n}^{\mathrm{o}} 14, \mathrm{p} .123$.

25 LUHMANN, Niklas, Confianza, Trad. FLORES, Amada, Barcelona: Antropos, 2005, p. 29 y ss. y especialmente 32 y ss.

${ }^{26}$ TÖNNIES, Comunidad y Asociación, cit. nota $\mathrm{n}^{\circ} 13, \mathrm{p} .14$.

27 VALENZUELA, Jonatan, "La narrativa del deber de ayudar a otro", cit. nota nº, p. 568 dirá acertadamente "la idea de vínculo entre miembros de la comunidad y, por tanto, la existencia de una determinada comunidad denota la presencia de la solidaridad como cuestión preinstitucional (...)”.

${ }^{28}$ Por eso la solidaridad conyugal que DURKHEIM, De la división del trabajo social, cit. nota $\mathrm{n}^{\circ}$ 14, p. 66, encuentra en la división del trabajo sexual no es propiamente solidaridad, sino más bien una asunción especial, un acuerdo.

${ }^{29}$ DURKHEIM, De la división del trabajo social, cit. nota ${ }^{\circ} 14$, p. 246.
} 
unión de voluntades orientada a subsistir la que cohesiona el grupo —admitiendo la incorporación de terceros que adscriban a ese fin-, las relaciones entre los integrantes alcanzan un nuevo nivel de complejidad, la solidaridad pierde esa pura naturalidad y emerge como una exigencia autónoma que informa las relaciones sociales. ${ }^{30}$

\subsection{La solidaridad social: la estructuración de la diferencia}

Si la solidaridad comunitaria se funda en las nociones de semejanza y pertenencia como eje de la acción común, hay un momento en que las relaciones sociales dan un paso hacia un mayor grado de complejidad. En este punto se ha observado más de una vez el paso desde la comunidad (Gemeinschaft) a una verdadera sociedad (Gesellschaft). ${ }^{31}$ La relación social se basa en una comunión de intereses motivados racionalmente, ${ }^{32}$ pero donde no hay una pertenencia natural sino más bien una estructuración que busca un fin común. Aquí se asiste a una ruptura del equilibrio social ${ }^{33}$ a la que sólo puede responderse con una diferenciación sistémica que sea capaz de procesar los nuevos niveles de complejidad social. Para esto se requiere, fundamentalmente, un entorno securitizado que impida la dinámica social propia de la comunidad de riesgos.

Para la consecución de los fines sociales ya no es esencial ni la semejanza ni una pertenencia en sentido estricto, sino por el contrario una organización que permita estructurar la diferencia y llevarla a niveles tolerables. ${ }^{34}$ Aquí surge, al decir de Hegel, La sociedad civil, que tiene tantas pretensiones sobre el individuo (deberes) como éste pretensiones de reconocimiento por parte de aquella (derechos). ${ }^{35}$ Por esta razón, como hito evolutivo, este paso tiene una característica fundamental, pues consecuencia natural de que la semejanza no sea la que cohesiona o estructura el grupo, es que hay una diferencia que debe soportarse. En otros términos, surge un imperativo de tolerancia de la diferencia - siempre que ella no se refieran al fin común que sí cohesiona al grupo-. La tolerancia por esa diferencia deja espacios de organización de los individuos en que los otros

\footnotetext{
${ }^{30}$ COMTE, Auguste, La filosofía positiva, México D.F.: Porrúa, 2003, p. 119 y ss. identifica este mometno como aquel en que los sentimientos decisivos en la familia — dentro de los que se encuentra la solidaridad-, se incorporan a la vida social. En una maravillosa lectura de la parábola del Buen Samaritano, WALDRON, Jeremy, "Who is my neighbour? Humanity and Proximity", The Monist vol. 86, №3, pp. 333-354, hace ver cómo el verdadero mensaje que hay en el pasaje no es la necesidad de solidaridad (que se presupone), si no la apertura de los destinatarios al resto de la humanidad.

${ }^{31}$ TÖNNIES, Comunidad y asociación, cit. nota ${ }^{\circ}{ }^{13}$, pássim y especialmente p. 5 y ss. DURKHEIM, De la división del trabajo social, cit. nota ${ }^{\circ} 14$, p. 217, veía como quiebre del equilibrio para el paso de la sociedad mecánica, a la orgánica (comunidad a sociedad en lenguaje de Tönnies) el aumento del volumen y densidad de la sociedad, al punto que la historia mostraría que sólo ha progresado la sociedad orgánica a medida que retrocede la mecánica.

${ }^{32}$ WEBER, Conceptos sociológicos fundamentales, cit. nota $\mathrm{n}^{\circ} 12, \mathrm{p} .146 \mathrm{y}$ ss.

${ }^{33}$ DURKHEIM, De la división del trabajo social, cit. nota $\mathrm{n}^{\circ}$ 14, p. 217. A esto en Rol social y sistema de imputación, Barcelona: Bosch, 2005, p. 204, hemos denominado "quiebre del equilibrio de especialización".

${ }^{34}$ Por eso LUHMANN, La moral de la sociedad, cit. nota $n^{\circ} 4$, p. 16 dirá que la "desigualdad aun soportable" se transformará en la medida de la solidaridad.

${ }^{35}$ Grundlinien, §238: "La sociedad civil, sin embargo, arranca al individuo de ese vínculo [el de la familia, todo sustancial al que compete la previsión (...) respecto de su subsistencia y mantenimiento en caso de incapacidad sobrevenida], aleja sus miembros unos de otros y los reconoce como personas autónomas (...). Así se ha convertido el individuo en hijo de la sociedad civil, la cual tiene tantas pretensiones sobre él como derechos tiene él ante ella".
} 
(individualmente) y el grupo no pueden tener ni presencia ni injerencia y por eso en alguna ocasión se ha afirmado que el añadido fundamental del paso de la comunidad a la sociedad es la exclusión. ${ }^{36}$ En este punto las esferas de dominio de cada integrante se encuentran deslindadas y sólo se coordinan artificialmente (y la intrusión en ámbitos ajenos comienza a considerarse un acto hostil). Luego, no hay ya una repetición de segmentos similares y homogéneos, sino que comienza el camino a la diferenciación de un sistema de órganos, cada uno con funciones especiales, coordinados y subordinados unos a otros. ${ }^{37}$

En esta etapa, sin embargo, la solidaridad sigue jugando un papel fundamental, si bien ahora su fundamento es estrictamente social y está vinculado al fin que ordena a la sociedad y no a las relaciones naturales entre los miembros. CICERÓN lo indicaba certeramente en de Oficci, cuando equiparaba sin contratiempos en esta etapa los dos tipos de deberes generales: "hay dos tipos de injusticia, el primero de quien injuria a otro, y el segundo, de aquellos que pudiendo no defienden a los injuriados". 38

Sin embargo, es evidente que el surgimiento de la exclusión como propiedad emergente produce un efecto de relegación relevante sobre la solidaridad mecánica propia de la comunidad. El incremento de la complejidad social (anonimización de las relaciones sociales) produce una reducción de la familiaridad y ello exige buscar otras formas de generalización para obtener confianza, es decir, para esperar cosas de los otros. ${ }^{39}$ En esa búsqueda de generalización y de certezas acerca de qué esperar de otros que ya no conocemos, comienzan a reconocerse -y asignarse- ámbitos de incumbencia diferenciados por los que ha de responderse. Luego si bien la solidaridad aparece como una característica antropológico-social, ${ }^{40}$ la estructuración de la sociedad delimitando ámbitos precisos de incumbencia y desempeño social (división del trabajo) termina reduciendo sus espacios. Este es el momento evolutivo en que, como ha dicho JAKOBS, ya "no todo es asunto de todos" (nicht jedes alles angeht). ${ }^{41}$

En este proceso evolutivo, la primera forma conocida de división de ámbitos se da en el marco de la estratificación social, lo que sin duda produce un quiebre en la distribución de la solidaridad, relegándola a una solidaridad intra-estratos. Posteriormente, resulta relativamente visible que a partir del Siglo XVI la diversidad social comienza a incrementarse exponencialmente a costa de la unidad (incluso dentro de los respectivos

\footnotetext{
36 TÖNNIES, Comunidad y asociación, cit. nota $\mathrm{n}^{\mathrm{o}} 13$, p. 14 y ss.

${ }^{37}$ DURKHEIM, De la división del trabajo social, cit. nota n ${ }^{\circ} 14$, p. 216 y ss.

${ }^{38}$ CICERÓN, Sobre los deberes, Madrid: Alianza 2012, p. 70.

${ }^{39}$ LUHMANN, Confianza, cit. nota n ${ }^{\circ} 25$, p. 36-37.

${ }^{40}$ El pensamiento de Durkheim en este punto es claramente tributario de Pierre Leroux (1797-1871). Esta misma noción la haría suya Auguste Comte. Vid. FERNÁNDEZ SEGADO, Francisco, "La solidaridad como principio constitucional", cit. nota $\mathrm{N}^{\circ}$ 15, p. 140; AMENGUAL, Gabriel, "La solidaridad como alternativa. Notas sobre el concepto de solidaridad", RIFP, n¹ (1993), pp.135-151, p. 136; GÓMEZ PAVAJEAU, Carlos Arturo, "La solidaridad en la antigüedad y la dogmática de la omisión”, Derecho Penal y Criminología, vol.26, no 77 (2005), pp.137-226.

41 JAKOBS, Günther, "La imputación objetiva, especialmente en el ámbito de las instituciones jurídicopenales del riesgo permitido, la prohibición de regreso y el principio de confianza", en su Estudios de Derecho Penal, Trad. Cancio, Manuel “et al”, Madrid: Civitas, 1997, p. 211.
} 
estratos sociales) la que comienza a procesarse con dificultad y a valorarse negativamente. ${ }^{42}$ La consiguiente plusvalía, primero funcional y luego ética, de la diversidad, lleva consigo la atomización de las relaciones sociales y la solidaridad comienza a quedar relegada a un espacio cada vez menor, subsidiario y de emergencia.

Luego, desde esta perspectiva pueden distinguirse metodológicamente cuando menos tres $\operatorname{etapas}^{43}$ :

Comunidad estructurada sobre la base de solidaridad mecánica o natural. En ella los deberes positivos solidarios se encuentran indiferenciados o protodiferenciados y llegan a confundirse con el deber de no dañar a otros.

Comunidad sustentada en un proyecto colectivo de supervivencia y desarrollo. En ella la solidaridad ya no descansa en relaciones parentales sino en un acuerdo civil desvinculado de las posiciones pero fundadas en una adscripción voluntaria a la comunidad. Solo en este estadio surge la solidaridad como principio que informa la vida social y que puede recogerse jurídicamente. Sólo aquí hay suficiente complejidad social como para que la solidaridad aparezca como una propiedad emergente y pueda diferenciarse de otros deberes positivos mecánicos. El último estadio de esta estructuración social es la sociedad estratificada.

Sociedad diferenciada funcionalmente. La diferenciación se hace más densa, se fortalece la exclusión de ciertos ámbitos de incumbencia. Los deberes institucionales van ganando

\footnotetext{
${ }^{42}$ LUHMANN, Niklas, ¿Cómo es posible el orden social?, México D.F.: Herder, 2009, p. 51 y ss. Si desde Aristóteles había sido la amistad — y connaturalmente, la solidaridad como su fruto más propio-el concepto para describir las relaciones positivas tanto privadas como públicas entre las personas ${ }^{42}$ esta mirada comienza a resquebrajarse. ARISTÓTELES, Ética Nicomaquea, Gredos, Madrid 2000, p. 253 [1167a] dirá: "La benevolencia se parece a la amistad, pero no lo es. Es su comienzo. Una disposición previa que se da incluso hacia personas desconocidas". Que la solidaridad fuera ese fruto más propio, resultaba profundamente natural en la medida que el hombre en su teoría ética y política se encontraba a sí mismo y a los demás viviendo en la ciudad (como comunidad autárquica). Esto queda plasmado fundamentalmente en los Libros VIII y IX de la Ética Nicomaquea, cit. nota $n^{\circ} 42$, dirá en la p. 237 [1166b] que es a la comunidad a la que se atribuye toda amistad, entre ciudadanos, miembros de una misma tribu, compañeros de navegación y que parece estar basada en una especie de acuerdo. Vid RITTER, Joachim, Metaphysik und Politik, Studien zu Aristoteles und Hegel, Frankfurt a.M.: Suhrkamp, 1969, pp. 57 -105. Durkheim se hará eco expresamente de esta misma formulación en la División del Trabajo Social, cit. nota $\mathrm{N}^{\circ} 14$. Vid., además, LUHMANN, La moral de la sociedad, cit. nota $\mathrm{n}^{\circ}$ 4, p. 19. Luego, dirá LUHMANN, La moral de la sociedad, cit. nota $\mathrm{n}^{\circ}$ 4, p. 55., la amistad comienza a relegarse a los ámbitos privados y si bien continúa informando el relato cohesionador de lo social, comienzan a elevarse los requisitos para que esa amistad sea socialmente vinculante. Después de la pérdida de todo contenido religioso - la cohesión como un orden debido-, lo común debió ser reconstruido y la idea de un contrato fue lo suficientemente plástica para cumplir ese objetivo: se cohesionan los intereses divergentes a partir de las compatibilidades reconocibles. Queda fijado a partir de ahí el marco de lo público y esa amistad, que seguirá informando las relaciones sociales, encontrará su espacio únicamente en los pliegues de la discreción, la intimidad y lo privado.

${ }^{43}$ Lo que resulta absolutamente evidente simplemente del hecho de poder identificar etapas es que, como ha dicho VALENZUELA, "La narrativa del deber de ayudar a otro", cit. nota n 1, p. 571: "no es en ningún sentido 'natural' que lo que le pase al vecino "no sea mi asunto",.
} 
terreno a costa de la marginalización de los deberes solidarios. En este estadio la complejidad social induce a la sumergencia de los deberes de solidaridad. ${ }^{44}$

\section{La solidaridad como problema jurídico}

\subsection{Fundamentos jurídico-políticos y Solidaridad}

El Derecho inevitablemente es tributario de los cambios sociales y las ciencias jurídicas comienzan a hacer esfuerzos por incorporar un aparataje conceptual coherente. Burgueois, al publicar su influyente opúsculo Solidarité (1896) entiende que la solidaridad social (con sus alcances y limitaciones) encuentra sus raíces en esa solidaridad natural propia de la comunidad $^{45}$ y sienta las bases para entenderla como un derecho exigible jurídicamente. ${ }^{46}$ Duguit, por su parte, tomaría el principio para hacerlo extensivo al ámbito jurídico fundando obligaciones para el Derecho público con la noción de que toda sociedad implica solidaridad y toda regla de conducta que toca a los hombre que viven en ella ordena cooperar con dicha solidaridad. ${ }^{47}$ En otros términos, si la sociedad tiene ciertas necesidades estructurantes que penden de la solidaridad de sus miembros, no solo no existe impedimento alguno para que el Derecho pueda exigir esas prestaciones, sino que incluso su consagración puede entenderse como un imperativo. De hecho, el fundamento político que dotaría de legitimidad las obligaciones jurídicas descansa cómodamente en los ideales de la revolución francesa, que incorporaba la solidaridad a través de la "fraternidad" como valor fundante y que precisamente hacía referencia a esa asistencia recíproca que se deben los ciudadanos.

Precisamente a partir de dichos ideales ilustrados, es relativamente evidente que el camino del concepto de solidaridad comienza un marcado proceso de laicización que intenta alejarlo de la caridad como virtud. ${ }^{48}$ Así la Caritas (como mandato divino de amor al

\footnotetext{
${ }^{44}$ BUSTOS RUBIO, Miguel, "Bien jurídico y sanción penal en el delito de omisión de socorro", Revista de Ciencias Jurídicas y Sociales (FORO, nueva época), $\mathrm{n}^{\circ} 15$ (2) (2012), pp. 157-183, p. 160 y ss. sostiene que el proceso de sumersión de los deberes de solidaridad se muestra en que la argumentación de las líneas argumentativas solidarísticas comienzan a hacerse implausibles frente a la vocación por la protección de la seguridad de la persona. Hace notar, de hecho, que la valoración de la solidaridad como bien jurídico susceptible de protección penal apenas duró 26 años pues en Código penal de 1822 aparece como delito pero ya en el de 1848/1850 ya aparece como una falta.

${ }_{45}$ Cfr. BLAIS, Marie-Claude. La solidarité. Histoire d'une Idee, Paris: Gallimard, 2007, pássim. Vid, también, HERRERA, Carlos Miguel, "El concepto de solidaridad y sus problemas político-constitucionales. Una perspectiva iusfilosófica", Revista de Estudios Sociales n 46 (2013), pp. 63-73.

${ }^{46}$ FERNÁNDEZ SEGADO, "La solidaridad como principio constitucional", cit. nota no 15, p. 144.

${ }^{47}$ DUGUIT, León, Traité de Droit Constitutionnel: Tomo III. $3^{a}$ ed., París: De Brocard, 1928, p. 640-641, quien transpone los principios de la solidaridad orgánica durkheimiana al Derecho público fundamentando el Derecho mismo en la solidaridad o la mutua dependencia social. Vid. HERRERA, "El concepto de solidaridad y sus problemas político-constitucionales", cit. nota $n^{\circ} 45$, p. 67; FERNÁNDEZ SEGADO, "La solidaridad como principio constitucional", cit. nota $\mathrm{n}^{\circ} 15, \mathrm{p} .144$.

${ }^{48}$ Sin perjuicio del ostensible menor desarrollo tanto dogmático como filosófico-político que tiene el concepto de solidaridad/fraternidad frente a los de igualdad o libertad. Vid. AMENGUAL, "La solidaridad como alternativa", cit. nota n 40, p. 136; PECES-BARBA, Curso de Derechos Fundamentales, I, cit. nota n ${ }^{\circ} 15$, p. 145.
} 


\section{PIÑA, Juan Ignacio, "La solidaridad como fuente de deberes. Elementos para su incardinación en el sistema jurídico penal”.}

prójimo) se distingue de la Solidaritas (como imperativo humano). ${ }^{49}$ Sin embargo, este contenido de la solidaridad todavía impreciso encuentra su desarrollo dogmático principalmente en el sentido amplio de la asistencia que se debe a los desposeídos, alentando más bien una cooperación en ese ámbito lo que permitía un suave y expedito tránsito desde la obligación moral a la obligación jurídica. ${ }^{50}$

La búsqueda de los fundamentos políticos de la solidaridad también ocupó a la tradición liberal (e incluso proto-liberal ${ }^{51}$ ) anglosajona — especialmente la de raigambre utilitarista. Si hemos dicho que la sociedad se estructura a partir de un cierto orden que la cohesiona, la solidaridad juega un papel ineludible. Hume ya había puesto de relieve que las virtudes sociales, como la beneficencia, son útiles. ${ }^{52}$ Lo mismo explica que John Stuart Mill tampoco haya podido abstraerse de ella, pues si el objetivo general de la sociedad es conseguir el mayor bienestar posible para la mayor cantidad de gente posible, ${ }^{53}$ la asistencia de los más necesitados, para cumplir dicho axioma, no puede prescindir de la solidaridad. ${ }^{54}$ A mayor abundamiento dirá "el utilitarismo exige a cada uno que entre su propia felicidad y la de los demás, sea un espectador tan estrictamente imparcial como desinteresado y benevolente. En la norma áurea de Jesús de Nazaret, leemos todo el espíritu de la ética utilitarista. Haz como querrías que hicieran contigo y ama a tu prójimo como a ti mismo".55 Por eso a pesar de estructurar la justificación a la coactividad (imposición jurídica) sólo para asegurar la prohibición del daño a otro ${ }^{56}$ reconoce que hay acciones beneficiosas a las que se puede ver justamente obligado como testificar en juicio, participar de la defensa común, salvar la vida de un semejante, proteger contra abusos a los indefensos. ${ }^{57}$ Resulta

\footnotetext{
${ }^{49}$ BLAIS, La solidarité, cit. nota $\mathrm{n}^{\mathrm{o}} 45$.
}

${ }^{50}$ El Marqués de Condorcet (1743-1794) inspirará el primer reconocimiento jurídico-político (incluso constitucional) de la solidaridad. Sobre esto vid. FERNÁNDEZ SEGADO, "La solidaridad como principio constitucional", cit. nota ${ }^{\circ}$ 15, p. 143 y DE LUCAS, Javier, "La polémica sobre los deberes de solidaridad. El ejemplo del deber de defensa y su posible concreción en un servicio civil”, Revista del Centro de Estudios Constitucionales, $\mathrm{n}^{\circ} 19$ (1994), pp. 9-88, p. 18.

${ }^{51}$ LOCKE, John, en el Capítulo II del Segundo Tratado del Gobierno Civil, Trad. MELLIZO, Madrid: Alianza, 2007, Cap. 2, § 5. haciéndose eco de Richard Hooker menciona expresamente como consecuencia de la igualdad natural, la obligación de amarse mutuamente sobre la cual "se basan los deberes que tenemos para con los otros". De este modo, y como veremos, desde sus raíces la tradición liberal clásica tenía presente e incluso presuponía los deberes de solidaridad ciudadana. Continuará en el Cap $7, \S 77$ haciendo notar que Dios, al hacer al hombre una criatura que según el juicio divino no era bueno que estivera sola, lo puso bajo fuertes obligaciones tanto de necesidad como de conveniencia que lo invitaban a vivir en sociedad.

${ }^{52}$ Así expresamente en HUME, David, Investigación sobre los principios de la Moral, Trad. LÓPEZ SASTRE, Madrid: Espasa Calpe, 1991, p. 45 y EL MISMO, Tratado de la Naturaleza Humana, Madrid: Tecnos, 2013, p. 769.

${ }^{53}$ MILL, John S., El utilitarismo. Un sistema de la Lógica: Libro VI, Capítulo XII, Trad. GUISÁN, Madrid: Alianza, 2014, p. 48 y ss., 57.

54 Sobre esto resulta notable el trabajo de BOUCSEIN, Hildegard, John Stuart Mill und der Idee der Solidarität, Frankfurt a.M.: Fischer, R.G., 1983. Por eso BERLIN, Isaiah, John Stuart Mill y los fines de la vida (prólogo a On Liberty), Madrid: Alianza 2007, p.22 sostiene que Mill dio por supuesta la solidaridad humana (tal vez incluso con demasiada fe). Vid., además, AMENGUAL, "La solidaridad como alternativa", cit. nota $\mathrm{n}^{\circ} 40$, p. 137.

${ }^{55}$ MILL, El utilitarismo, cit. nota $\mathrm{n}^{\circ} 53$, p. 66.

${ }^{56}$ MILL, John S., Sobre la Libertad, Madrid: Edaf, 2014, p. 52

57 MILL, Sobre la Libertad, cit. nota $\mathrm{n}^{\circ}$ 56, p. 55. Trata, además y especialmente, el principio de la contribución haciendo presente que "los seres humanos deben ayudarse entre sí para distinguir lo mejor de lo 
muy interesante la incorporación de una obligación de socorro conjuntamente con la participación de la defensa común, especialmente considerando que ésta última sí puede exigirse coactivamente.

Por su parte el máximo representante del liberalismo clásico, Adam Smith, no pudo sino detenerse también en la solidaridad. La lectura exclusiva de An Inquiry into the Nature and Causes of the Wealth of Nations (conocida fundamentalmente como La Riqueza de las Naciones), publicada en 1776 y que sin duda es su obra más señera, influyente y citada ha solido perder de vista que dicho trabajo no resulta concebible sin la monumental obra previa The Theory of moral sentiments (La teoría de los sentimientos morales ${ }^{58}$ ) de $1759 .{ }^{59}$ En ella, deja expresamente señalado que - a diferencia de la competencia divina - a los hombres ha tocado un departamento de incumbencia más modesto: el cuidado de su propia felicidad, de la de su familia, de la de sus amigos y de la de su país. ${ }^{60}$ Por ello, incluso la creencia en una mano invisible y en el hecho de que del interés propio buscado emanara mayor bien para los otros no significa que fuera el único modo de alcanzar ese bien y que hay ciertos ámbitos donde la felicidad se encuentra en la beneficencia. ${ }^{61}$ Se sirve de la

peor y animarse unos a otros para optar por lo primero y evitar lo segundo" (p.173) dando cuenta de que en caso alguno propone un individualismo indiferente.

${ }^{58}$ SMITH, Adam, Teoría de los sentimientos morales, Madrid: Alianza, 2013. Esta edición usa de base la sexta edición de la obra, publicada en dos volúmenes en Londres/Edimburgo en 1790.

${ }^{59}$ Por eso no parece acertada la afirmación de PECES-BARBA, Curso de Derechos Fundamentales, cit. nota $\mathrm{n}^{\mathrm{o}} 15$, p. 222 y ss. y VIDAL GIL, Ernesto, "Sobre los derechos de solidaridad del Estado liberal al social y democrático de Derecho", Anuario de filosofía del derecho, n 10 (1993), pp. 89-110, p. 92, de que la solidaridad moderna aparece como una reacción al liberalismo descarnado de los fisiócratas y, de modo muy particular, los economistas británicos Adam Smith (1723-1790) y Thomas Robert Malthus (1766-1834), pues en lo que a Smith — que no a Malthus — se refiere, más bien se debería a la lectura parcial de su obra, que ha prescindido de aquella que le sirve de base de comportamiento humano antes de acometer la acción de intercambio que genera riqueza. Del mismo modo, sí es efectivo que en otros pensadores de lo que se podría llamar la escuela escocesa como FERGUSON, Adam, An essay on the history of civil society (1767), Edimburgo: Edinburgh University Press, 1966, p. 37 la solidaridad juega un papel sólo limitado a la mera liberalidad: "mientras los negocios se conducen con el máximo de autopreservación, las horas libres se dispensan a la amabilidad y la generosidad". Lo mismo puede decirse de HUME, Tratado de la Naturaleza Humana, cit. nota $\mathrm{n}^{\circ} 52$, p. 487. Coinciden sin embargo todos en que la mirada exclusivamente egoísta de la acción humana sin consideración de sympathy es miope. Vid. sobre esto GALLO, Ezequiel, "La tradición del orden espontáneo: Adam Ferguson, David Hume y Adam Smith”, Revista Libertas IV (6) (1987), pp. 1-15.

60 "[T] he care of his own happiness, of that of his family, his friends, his country", SMITH, Teoría de los sentimientos morales, cit. nota $\mathrm{n}^{\circ} 58$, p. 412. Esta frase en ocasiones ha sido leída como una limitación egoísta del alcance de estos deberes (Así, por ejemplo, ARRIAGADA, Genaro, Los empresarios y la política, Santiago: Lom, 2004, p. 25 y ss.), sin embargo, ello pierde de vista que además de estar tratado en la sección referida a la beneficencia universal (que en general compete — según Smith — a Dios), sí menciona ámbitos de incumbencia no propios y que además debe complementarse con otras menciones donde queda claro que sí dan cuenta deberes de esta naturaleza en relación con los desafortunados. Ya antes había dicho en la p. 395: "Después de los individuos que están encomendados a nuestra beneficencia, sea por su relación con nosotros, por sus cualidades personales o sus servicios pasados, vienen aquellos que no son objeto de nuestra amistad sino de nuestra atención benevolente y buenos oficios, los marcados por una situación extraordinaria, los muy afortunados y los desafortunados, los ricos y poderosos y los pobres y míseros". Vid. También GUTIÉRREZ RODRÍGUEZ, Germán, Ética y economía en Adam Smith y Friederich Hayek, México: Universidad Iberoamericana, 2008, p. 84 especialmente en nota 40.

${ }^{6}$ SMITH, La teoría de los sentimientos morales, cit. nota $n^{\circ} 58$, p. 395 dirá "el alivio y consuelo del infortunio humano dependen totalmente de nuestra compasión hacia los [desafortunados]". Y más adelante "por más que el hombre tenga rasgos egoistas, existen evidentemente en su naturaleza principios que lo 
expresión incumbencia (comprehension) que da cuenta de que esos ámbitos son su asunto y poniendo en la misma lista el cuidado propio y el de su país/localidad (Country). Al igual que en la tradición de Hume ${ }^{62}$ y Mill, no se detiene detalladamente en la solidaridad —ni deja claro dónde termina el deber ético y comienza la obligación-, pero la presupone como eje fundamental de la convivencia social. ${ }^{63-64}$

\section{2. ¿De qué hablamos cuando hablamos de solidaridad?}

\subsubsection{Generalidades}

Uno de los principales problemas que presenta la valoración de la solidaridad como fuente de deberes es su propia conceptualización. ${ }^{65}$ Habitualmente ésta se presupone de un modo más bien intuitivo o se enuncian sus señas características, pero su conceptualización suele ser ambigua y teóricamente insuficiente. ${ }^{66}$ Por esta razón — fuera del ámbito penal, que se limita al tratamiento de la omisión de socorro y de los deberes de tolerancia emanados del estado de necesidad agresivo- suelen entremezclarse bajo un mismo concepto deberes muy diversos que van desde el deber de socorro en naufragio, las obligaciones tributarias, las obligaciones de contribución en ciertos sistemas de pensiones, el servicio militar obligatorio, e incluso los deberes de cuidado del medio ambiente (como solidaridad transgeneracional). Sin embargo, la pregunta acerca de qué tienen en común estos deberes, más allá de las intuiciones y el tratamiento dispar que le dan distintos subsistemas del

interesan en la suerte de los otros y que hacen que la felicidad de ellos le sea necesaria, por más que no derive nada de esto, salvo el placer de poder contemplarlo". La beneficencia, para Smith, es la virtud por excelencia, la que debería primar por sobre el resto de nuestros afectos. Vid., sobre esto, RAMOS TORRES, Ramón, "La más melancólica de las reflexiones. Simpatía virtud y fortuna en 'La teoría de los sentimientos morales' de Adam Smith", Política y Sociedad, Vol. 37 (2001), pp. 21-46, p. 28 y ss.

${ }^{6}$ De hecho, HUME, Tratado de la Naturaleza Humana, cit. nota no 52, p. 798 había usado palabras extremadamente similares: "la generosidad de los hombres es limitada, extendiéndose pocas veces más allá de las familias o amigos o, todo lo más, del país natal".

${ }^{63}$ Resulta muy indiciario el propio título de la sección que SMITH, La teoría de los sentimiento morales, cit. nota $\mathrm{n}^{\circ} 58$, p. 385 dedica a este asunto (si bien inicialmente se refiere a las relaciones familiares, abarca al final de la sección a terceros): "The order in which individuals are recommended by nature to our care and attention" ("El orden en que los individuos son encomendados por la naturaleza a nuestro cuidado y atención"). De cualquier modo termina mostrando escepticismo respecto de que pueda ser exigida compulsivamente. Vid. RAMOS TORRES, "La más melancólica de las reflexiones", cit. nota n 61, p.31. Si bien someramente, menciona también la compatibilidad con el programa teórico de Adam Smith, LUHMANN, La moral de la sociedad, cit. nota $\mathrm{n}^{\circ}$ 4, p. 39.

${ }^{64} \mathrm{Sin}$ perjuicio de ello, es evidente que ni en esta época ni tampoco bien entrado el Siglo XX, había cabida en la tradición del Common Law para que este tipo de infracciones diera cabida a responsabilidad penal. Lord MACAULAY, Thomas, Speeches and poems, with the report and notes on the Indian penal law, Vol. 2, Nueva York: Hurd and Hughton, 1867, p. 408: "La ley penal debe contentarse con evitar que los hombres se hagan daño, y debe dejar a la opinión pública, y a los profesores de moral y de religión, la tarea de proveer a los hombres de razones para hacer positivamente el bien" ("The penal law must content itself with keeping men from doing positive harm, and must leave to public opinion, and to the teachers of morality and religion, the office of furnishing men with motives for doing positive good"). Vid también STEPHEN, A history of the criminal law of England, Londres 1885, vol. 3., p. 10; ASHWORTH, Positive obligations in criminal law, cit. nota $\mathrm{n}^{\mathbf{0}}$ 3, p. 39. Sobre esto nos hemos detenido en PIÑA ROCHEFORT, Juan Ignacio, La estructura de la teoría del delito en el ámbito jurídico del Common Law, Granada: Comares, 2002.

${ }^{65}$ VAN WEEZEL, Alex, "Solidaridad en el tráfico motorizado", cit. nota n 2, p. 194.

${ }^{66}$ HOELZL, Michael, "Recognizing the sacrificial victim", cit. nota $n^{\circ} 17, \mathrm{p} .45$. 
Derecho, no suele encontrarse de un modo explícito. Las razones para esto son diversas. Por un lado, la intuitiva - aunque no por ello no bien descripta - marginalización de los deberes solidarios en nuestros ordenamientos jurídicos. Por otro, la difundida asunción de que los deberes de solidaridad jurídicamente conminados deslindan dificultosamente con deberes éticos inexigibles por parte del Derecho por significar intromisiones inaceptables en la esfera individual del ciudadano.

Varias consideraciones habría que hacer al respecto antes de abordar las características de la solidaridad. En primer lugar, es efectivo que hay un ámbito de la solidaridad que pertenece exclusivamente a las prescripciones del sistema moral y que, por ende, no tiene un reconocimiento jurídico que la respalde. Ello quiere decir que no es susceptible ni de reconocimiento ni de sanción por parte del ordenamiento jurídico. Hay un segundo ámbito de deberes de solidaridad que son tematizados por el sistema jurídico y respecto de ellos es posible encontrar mecanismos tanto de reconocimiento como de sanción. Dentro de éstos, por último, es posible encontrar algunos deberes jurídicopenalmente conminados. Por razones evidentes, los deberes de solidaridad tematizados exclusivamente desde la perspectiva moral están completamente fuera del alcance de estas notas. De cualquier modo, no es posible perder de vista que las fronteras entre el sistema de la moral y el sistema jurídico son evolutivamente dinámicas, lo que permite que ciertos deberes puedan convertirse en jurídicos si dicho sistema comienza a tematizarlos según sus propias operaciones. Luego, solo nos referiremos aquí a aquellos deberes tematizables por el Derecho poniendo algunas notas en aquellos que son de resorte del Derecho penal.

Más allá de consideraciones de carácter ético-social, desde la perspectiva jurídica hablar de deberes de solidaridad es referirse a unos ciertos (1) deberes positivos dirigidos a beneficiar a (2) terceros o con los que no estamos vinculados por alguna razón institucional ni por algún deber emanado del neminem laedere o (3) a la colectividad toda. ${ }^{67}$ En este sentido, y solo en un plano descriptivo, sólo hay espacio a la solidaridad ahí donde no hay otro deber prevalente. Probablemente este mismo hecho sea el que ha producido el sesgo de lo residual, relegando en nuestro entendimiento a la solidaridad a una forma de deber de inferior jerarquía.

Varias consecuencias emanan de estas nociones. Primero, hablamos de un beneficiario porque resulta muy discutible que quién reciba (o aspire a recibir) la prestación o tolerancia, sea realmente un acreedor, aunque puedan esperar (tener una expectativa legítima) de recibirla. ${ }^{68}$ Quién se encuentra en peligro de perecer no es acreedor del auxilio (y no tiene herramientas jurídicas para exigirlo), sin perjuicio de que el Estado sancione posteriormente a aquel que pudiendo sin detrimento ha decidido no auxiliarlo. Otro tanto ocurre con aquel que puede esperar que el titular de un derecho tolere su lesión para resolver una situación de necesidad.

\footnotetext{
${ }^{67}$ Es evidente que no todos los deberes de solidaridad jurídicamente reconocidos son susceptibles de sanciones penales para el caso de su contravención. Nos referiremos aquí sólo a éstos últimos.

${ }^{68}$ Vid. GARZÓN VALDÉS, Ernesto, "Los deberes positivos generales y su fundamentación”, Doxa, no 3 (1986), pp. 17-33, p. 20. Del mismo modo, DE LUCAS, "La polémica sobre los deberes de solidaridad", cit. nota $\mathrm{n}^{\circ} 50, \mathrm{p} .38$.
} 


\section{PIÑA, Juan Ignacio, "La solidaridad como fuente de deberes. Elementos para su incardinación en el sistema jurídico penal”.}

Otra cuestión, es que nos apartamos de la idea de identificar a los deberes positivos con deberes solidarísticos. ${ }^{69}$ De este modo, no todo deber positivo es solidario, y que todo deber solidario sea positivo tampoco parece tan claro. Desde esta perspectiva, tal vez sea posible que la forma concreta que adopte la solidaridad pueda ser tanto la de un deber positivo como uno negativo. Veamos con algo más de detalle algunas de estas cuestiones.

\subsubsection{Deberes negativos, deberes positivos y Solidaridad: esbozando una taxonomía}

La distinción entre los deberes positivos y negativos, ${ }^{70}$ a pesar de ser relativamente fácil de intuir no es necesariamente fácil de dotar de contenido. Desde sus formulaciones originales estaba incardinada en el código binario bien/mal (hacer el bien como deber positivo, evitar el mal como deber negativo). Desde dicho punto de partida, en ocasiones se entiende el deber positivo como aquel deber de contribuir al bienestar de los demás, esto es, un deber para con el otro o la colectividad, mientras que el deber negativo es un deber intersubjetivo de respeto al otro. ${ }^{71}$

Como ya hemos indicado de entre los deberes positivos es decir, aquellos que implican la asistencia o mejoramiento de la posición de otro, hay algunos que tienen como fundamento la solidaridad y otros que no. Los primeros se refieren a (1) aquellos que se tienen respecto de terceros con los que no se tiene ninguna vinculación institucional que lo sostenga (es decir, respecto de los cuales no se tiene una posición de garante) o (2) respecto de la comunidad toda o del Estado, también en ausencia de una posición de garante institucional. Ejemplo de los primeros son la omisión de socorro o el deber de tolerancia emanado del estado de necesidad agresivo. Ejemplo de los segundos son el deber de testificar en juicio, de ser jurado en los ordenamientos que lo contemplan o el servicio militar obligatorio. ${ }^{72}$

\footnotetext{
${ }^{69}$ Aún cuando una noción amplia de solidaridad que los entendiera así sería plenamente coherente con el entendimiento general de DURKHEIM. En ese modelo, incluso el neminem laedere es expresión de la solidaridad humana.

${ }^{70}$ La distinción entre unos y otros ya puede encontrarse en la Summa Teológica de Santo Tomás de Aquino, III, 72,6; I-II, 100, 6; II-II, 79, 3. Sobre esto vid. ROBLES PLANAS, Ricardo, "Deberes negativos y positivos", cit. $\mathrm{n}^{\circ} 1$, p. 3 y ss.

${ }^{71}$ ROBLES PLANAS, "Deberes negativos y positivos", cit. nota no 1, p. 5 y ss.; PAWLIK, Michael, Das Unrecht des Bürgers, cit. $\mathrm{n}^{\circ} 1$, p. 186 y ss.

${ }^{72}$ ASHWORTH, Positive obligations in criminal law, cit. nota $\mathrm{n}^{\mathrm{o}} 3$, p. 43, bajo el rótulo de deberes cívicos (civic obligations) menciona en el ámbito del Common Law: (1) deber de asistir a la autoridad para hacer efectiva la ley penal cuando es requerido; (2) Deber de notificar a la autoridad cuando hay sospecha de actos terroristas; (3) Deber de algunos profesionales de denunciar las sospechas de abusos sexuales infantiles; (4) Deber de las personas de hacer esfuerzos razonables por conocer el alcance de la ley penal. Evidentemente (1) y (2) son deberes solidarios perfectos; (3) es un deber institucional indexado a una posición y (4) es una derivación natural del principio neminem laedere. Bajo el rótulo de obligations arising from personal responsibility, incorpora el deber del dueño de un predio de impedir delitos que se cometan en él, que también es un deber solidario. Por último, bajo el rótulo de voluntary incurred obligations incorpora los deberes emanados de participar en ciertas actividades (desde el tráfico rodado hasta actividades comerciales o financieras) que imponen obligaciones positivas. Luego, más allá de las discrepancias taxonómicas que podrían identificarse, el reconocimiento de deberes positivos solidarios y generadores de responsabilidad penal distan mucho de la marginalidad que aún subsiste en el imaginario anglosajón.
} 
De entre los deberes positivos solidarísticos podrían distinguirse también aquellos que implican un ejercicio de solidaridad activa (intervenir para mejorar: omisión de socorro, servicio militar obligatorio, deber de evitar delitos) o solidaridad pasiva (tolerar para que otro pueda mejorar: deber de tolerancia en estado de necesidad agresivo).

Sin embargo, en cualquiera de los casos anteriormente citados se da por sentado que quien ostenta el deber carece de una posición especial que sea la que ponga el deber sobre sus hombros, es decir recaen sobre todos los ciudadanos indiferenciadamente. Evidentemente algunos de ellos deben cumplir algunos requisitos legales (como cumplir una cierta edad en el caso del servicio militar, o no estar excusado en el caso de la obligación de ser jurado), pero solventados esos requisitos todos los ciudadanos están obligados a ello.

Sin embargo, esta estructura de deberes también debe reconocer la existencia de deberes positivos especiales, que son aquellos indexados a una posición o, lo que lo mismo, a un rol institucionalizado. Así el deber que tiene el funcionario respecto de los dineros o documentos que tiene que resguardar, o el que tiene el curador de bienes, son deberes positivos que están indexados a la posición jurídicamente reconocida que ocupan. Estos deberes pueden tener o no un fundamento solidarístico, pero una vez asignado una posición se transforman en un deber institucional. A modo de ejemplo, es relativamente claro que el deber de cumplir el servicio militar obligatorio es un deber de cuño solidario, sin embargo, asumido el carácter de conscripto se cumple una función pública que se asigna a esa posición. Esos deberes son ciertamente deberes institucionales.

Por eso podemos decir que el proceso de institucionalización de roles también puede leerse como un proceso de sustracción del deber del ámbito solidarístico general para situarlo en el ámbito de un rol especialmente vinculado. En una comunidad en que unos vecinos por la ubicación de sus moradas y sus capacidades físicas se encargan de repeler los ataques de la comunidad vecina (obligación que indeterminadamente compete a todos los miembros de la comunidad) hay solidaridad en sentido más pleno. En el momento en que dicha comunidad se organiza y distribuye funcionalmente esos deberes, su cumplimento deja de ser solidarístico, aunque recaiga en las mismas personas, que ahora deben acometerlo por la posición institucional que ocupan (y que deben de seguir cumpliéndolo incluso si cambian las circunstancias que le dieron origen, como dejar de vivir en el lugar fronterizo).

Puesto de otro modo, el proceso de diferenciación social solo puede hacerse a costa de lo previamente indiferenciado. Si el proceso de división funcional de la sociedad produce o incrementa los ámbitos de exclusión, es inevitable que la complejización del entramado de relaciones sociales y su institucionalización vaya reduciendo los espacios a la solidaridad indiferenciada. Esto permite distinguir, por tanto, deberes positivos generales y deberes positivos especiales. Los primeros se adscriben a todos los ciudadanos mientras que los segundos sólo a aquellos que ocupan posiciones determinadas en el entramado de relaciones sociales.

Desde esta perspectiva puede ser deseable acotar el concepto de solidaridad precisamente hasta el momento en que ella no se cristaliza en la institución de un deber especial asociado a una posición. Rasgo distintivo de la solidaridad es la indiferenciación. Una vez que se 
diferencia la posición y se adscribe un deber especial ya no puede hablarse de solidaridad sino de una forma de deber positivo institucional que puede dar lugar tanto a omisiones puras de garante (si son calificados) u comisión por omisión. ${ }^{73}$ Estos son ya deberes institucionales, si bien pueden tener un fundamento originariamente solidario.

Estos deberes positivos especiales están adscritos a una posición. Pero como ya hemos adelantado, no todo deber positivo especial es solidarístico. No hay solidaridad entre madre e hijo o entre funcionario penitenciario y el encarcelado (aunque ambos deban especial y positivamente hacerse cargo del resguardo de aquellos). Aunque en ambos casos de trata de resguardar o mejorar la posición de otro, la vinculación de ellos está mediada institucionalmente (por la relación materno-filial o por la función pública que desempeñan). Con estas consideraciones aún podría darse un paso taxonómico adicional. Como hemos esbozado, existen múltiples deberes institucionales que tienen un origen solidarístico, como el pago de impuestos o la contribución a la defensa común a través de un servicio militar obligatorio. Sin embargo, a partir de la institucionalización de esos deberes y su adscripción a ciertas posiciones establecidas al efecto (como cumplir los requisitos para ser considerado un contribuyente o un recluta) lo que sostiene el deber ya no es su solidaridad de origen sino la institucionalización del rol adscrito a esa posición.

Esto nos permite adicionalmente distinguir dos formas distintas que puede presentar la contribución que se debe. Aquellos deberes que imponen una contribución directa a un afectado indeterminado, como en los casos de omisión de socorro, abandono de niños o auxilio en naufragio, etc. Por otra parte, pueden identificarse deberes solidarios que imponen contribuir directamente al Estado para que este pueda cumplir sus funciones (como el pago de impuestos, el servicio militar obligatorio, el auxilio a la autoridad, la obligación de ser jurado, etc.). Por último, dentro de estos últimos también hay algunos deberes solidarísticos indexados a una posición como al deber de auxilio al naufragio que tiene el capitán de la embarcación que se encuentra con la desgracia. ${ }^{74}$

\footnotetext{
73 Sobre estas distinciones vid. SILVA SÁNCHEZ, Jesús-María, La omisión. Concepto y sistema, Montevideo: B de F, 2003, p. 347 y ss.

${ }^{74}$ El artículo 914 número 10 del Código de Comercio le impone el deber de prestar la asistencia y auxilio a que esté obligado por las leyes o la costumbre. Así mismo, el Artículo 1135 dispone que "Todo capitán está obligado a prestar auxilio a cualquier persona que se encuentre en peligro en el mar. El dueño u operador de la nave no será responsable del incumplimiento de esta obligación del capitán". Por su parte, el artículo 102 de la Ley de Navegación dispone que "Toda nave tiene la obligación de acudir en auxilio de otra en peligro, salvo que ello represente un grave riesgo para su propia seguridad, la de su dotación o la de sus pasajeros. Esta obligación cesa en cuanto se haya logrado asegurar la vida de la dotación y de los pasajeros de la nave en peligro. El capitán que no cumpliere con este deber, será sancionado con la cancelación de su título, sin perjuicio de la responsabilidad penal que le afecte, a menos que justifique haber tenido una causa que razonablemente le haya impedido hacerlo. El armador o naviero no será responsable en este caso por el hecho de su capitán". Esta obligación consuetudinaria y legal tiene su fuente en los Rôles d'Oleron promulgadas por Leonor de Aquitania en 1160 publicadas en inglés por Enrique VIII como The Judgement of the sea, of Masters, of Mariners, and Merchants, and all their doing.
} 


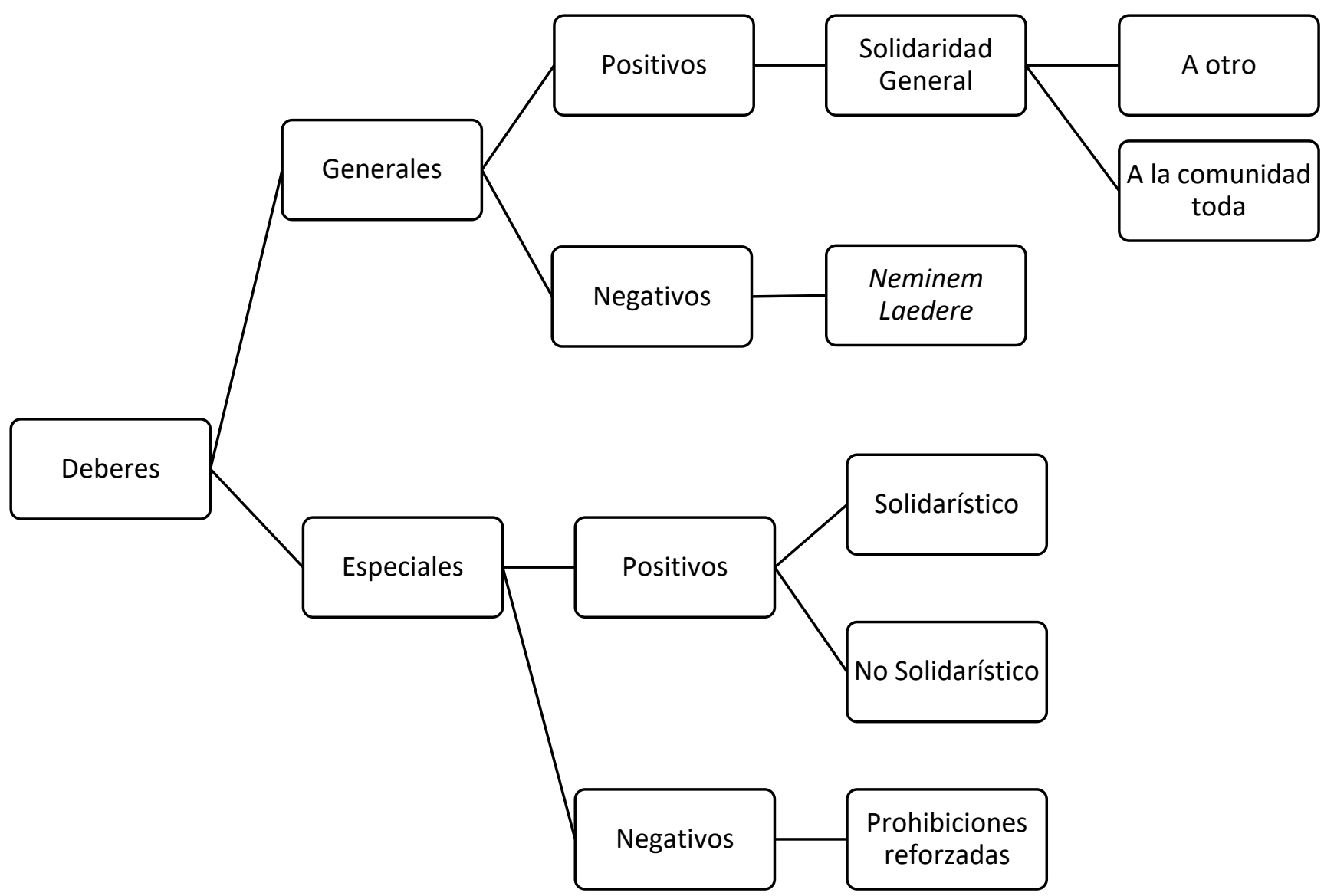

\subsubsection{La solidaridad como deber positivo general}

Hemos enunciado que al hablar de solidaridad nos referimos solo a aquellos deberes positivos generales y no a los que están indexados a una determinada posición. Esta toma de postura no puede olvidar que existen deberes asociados a posiciones que son auténticamente solidarísticos, como el del capitán de la nave que encuentra el naufragio. $\mathrm{Ni}$ el reconocimiento, ni las señas, ni la legitimidad de estos deberes positivos generales es pacífica ${ }^{75}$ De hecho, es posible que — constatada su consagración — gran parte de la discusión pueda sintetizarse en dos preguntas: (1) Son o no deberes perfectos o fuertes; (2) cuán legítimo es para el ordenamiento jurídico exigir deberes de este tipo.

\footnotetext{
${ }^{75}$ Baste para constatarlo la discusión plasmada en Doxa n ${ }^{\circ} 3$ (1986), p. 17-82, entre Garzón Valdés, Bayón, Laporta y James S. Fishkin. Vid., además, VARONA GÓMEZ, Derecho penal y solidaridad. Teoría y práctica del mandato penal de socorro, Madrid: Dykinson, 2005, pássim, y ofreciendo un sistema de limitaciones, p. 171 y ss.; MORGENSTERN, Unterlassene Hilfeleistung, Solidarität und Recht, cit. ${ }^{\circ}$ 1, p. 125; CADOPPI, "Failure to rescue and the continental criminal law", cit. n 1, p. 117; ALCÁCER GUIRAO, "Autonomía, solidaridad y deber de socorro", cit. nota n 1 , p. 362 y ss.
} 


\section{PIÑA, Juan Ignacio, "La solidaridad como fuente de deberes. Elementos para su incardinación en el sistema jurídico penal”.}

Los cuestionamientos fundamentales a la propia existencia de estos deberes se podrían resumir en (1) la inexistencia de alguien que pueda exigir su cumplimiento; (2) la imposibilidad de limitar su alcance por la infinitas posibilidades de asistencia imaginables: siempre se puede mejorar aún más la posición del otro; y (3) la propia ineficiencia de un deber indiferenciado que no permite que sean aquellos órganos especializados los que presten los auxilios requeridos. ${ }^{76}$ Esta última ineficacia restaría evidentemente legitimidad a una internación en las esferas individuales del obligado.

La discusión respecto de la perfección de estos deberes ya está presente en $\mathrm{Kant}^{77}$ y se centra en la ausencia de acreedores determinados con derechos subjetivos correlativos a ese deber, ${ }^{78}$ o siguiendo a Mill, aquellos en que si bien el acto es obligatorio, las ocasiones particulares de su realización quedan libradas a nuestra elección. ${ }^{79}$ Sin embargo, incluso en los deberes positivos generales, como el deber de socorro, el hecho de que no exista un acreedor determinado del auxilio, no rebaja en nada su carácter de deber perfecto. De ser así, lo mismo debería predicarse de los deberes positivos especiales que tienen sujeto indeterminado como el del médico responsable del turno en la Urgencia o el salvavidas en la playa (pues nadie) sabe previamente quien será el beneficiario de sus atenciones o salvamento.

La intensidad de estos deberes suele tener como línea de base la que se le reconoce a los deberes negativos. De esta forma, la contraposición entre ellos suele realizarse de un modo bastante ácido. Se han reconocido como señas fundamentales de los deberes negativos las siguientes $^{80}$ : (1) se trata de deberes mínimos imprescindibles para permitir la vida en sociedad; (2) Procuran reducir al máximo la injerencia en la esfera individual, permitiendo el mayor desarrollo posible de la autonomía personal; (3) Son deberes que rigen para todos y por lo mismo son auténtica expresión del principio de universalización.

Que la constatación de estos deberes no es suficiente para describir el entramado de deberes sociales resulta evidente y basta ver los deberes positivos especiales (y la responsabilidad institucional correlativa) para confirmarlo. ${ }^{81}$ La pregunta relevante es si la existencia de estos deberes se contrapone efectivamente a la de los deberes positivos generales o no. Disímiles tradiciones han visto posible esta compatibilidad. Leibniz ya hizo presente que hasta el más liberal —obviamente sin permitirse esta nomenclatura- reprocharía a aquel que no lo auxiliara de perecer pudiendo hacerlo con sólo mover su mano. ${ }^{82}$ Sin embargo, dicho reproche o incluso llegar a considerarlo su enemigo, aún no da pie para transformar al

\footnotetext{
${ }^{76}$ GARZÓN VALDÉS, Ernesto, "Los deberes positivos generales y su fundamentación”, cit. n 68, p. 17 y ss.

${ }^{77}$ KANT, Immanuel, Fundamentación para una metafísica de las costumbres, Trad. GARCÍA MORENTE, Manuel, San Juan: Pedro M. Rosario Barbosa, 2007.

${ }^{78}$ FEINBERG, Joel, "The Moral and legal responsibility of the bad samaritan", ponencia presentada en el $11^{\circ}$ Congreso mundial de filosofía del Derecho y filosofía social, citado en: GARZÓN VALDÉS, "Los deberes positivos generales y su fundamentación", cit. nota $\mathrm{n}^{\circ} 68, \mathrm{p} .21$.

${ }^{79}$ Ibíd.

${ }^{80}$ GARZÓN VALDÉS, “Los deberes positivos generales y su fundamentación”, cit. nº 68, p. 28.

${ }^{81}$ Nos hemos extendido en esto en PIÑA ROCHEFORT, Derecho penal, Fundamentos de la responsabilidad, cit. nota $\mathrm{n}^{\mathrm{0}} 4$, p. 147 y ss.

${ }^{82}$ LEIBNIZ, Gottfried, "Méditation sur la notion commune de la Justice", 1893, p. 55, citado en GARZÓN VALDÉS, "Los deberes positivos generales y su fundamentación”, cit. nota nº 68, p. 30.
} 
indolente y malvado en un obligado jurídicamente. Kant sí da pasos en esa línea si bien siempre con las dudas respecto de la perfección de dicho deber. "A pesar de que pudiera existir una ley general de acuerdo con esta máxima [existencia de la obligación de no dañar/inexistencia de la obligación de auxiliar] es imposible querer que una tal ley natural valga siempre. Pues una tal voluntad se contradiría a sí misma en lo que necesita del afecto y solidaridad de los otros (...), de la que se privaría". 83 Sin embargo, no es necesario discurrir sobre la base de imperativos categóricos para fundamentar estos deberes. La lógica utilitarista se ve obligada a reconocer los rendimientos de la solidaridad para la consecución de la mayor felicidad para la mayor cantidad posible de personas, lo que permite fundar sólidamente su legitimación. ${ }^{84}$

Pero la fervorosamente defendida incompatibilidad entre la consagración de estos deberes positivos generales y un modelo genuinamente liberal presupone más bien una cierta forma de dogmatismo. Sostener que nos hemos dado al Estado sólo para que asegure nuestro propio ámbito de incumbencia y exclusión es, además de miope, falso. Resulta del todo evidente que incluso en ocasiones, para proteger nuestro ámbito de incumbencia y nuestra esfera de autonomía, es precisamente necesario permitir internaciones en ellos. ¿Qué es la obligatoriedad de reclutamiento sino una condición de resguardo de las esferas de autonomía de los ciudadanos antes eventuales amenazas externas? Como ya lo hemos enunciado, consideraciones de este tipo hacen que la propia lógica liberal clásica haya presupuesto unos ciertos espacios entregados a la solidaridad mínima para garantizar esa libertad individual. Puesto en términos muy rústicos: como los muertos no son libres, para asegurar la libertad de los vivos a veces hay que imponerles a otros el deber de salvarlos.

Esto explica por qué John Harris sostiene que ambos deberes - positivos y negativosforman parte de un único deber de no dañar ${ }^{85} \mathrm{o}$, con otra nomenclatura, que Durkheim incorpore el neminem laedere dentro de la solidaridad. Ambos se dan cuenta que afirmar sin más la prevalencia de los negativos puede desafiarse perfectamente. Estas afirmaciones resultan coherentes si se entiende que la obligación de auxiliar resulta una forma específica y concreta de la obligación genérica de no dañar. De cualquier modo, parece tener mejores rendimientos descriptivos la mantención de la distinción entre deberes negativos (no dañar) y deberes positivos de auxilio.

Por otra parte, el problema de la legitimación de la juridificación de estos deberes —y muy especialmente de su incriminación - ha discurrido en general por dos vías. Primero la descalificación de su legitimidad por una supuesta incompatibilidad con un modelo liberal del Derecho penal. ${ }^{86}$

\footnotetext{
${ }^{83}$ KANT, Fundamentación para una metafísica de las costumbres, cit. nota $\mathrm{n}^{\mathrm{o}} 77$, p. 37.

${ }^{84}$ Vid. VAN WEEZEL, "Solidaridad en el tráfico motorizado", cit. nota n ${ }^{\circ}$ 2, p. 202-203.

${ }^{85}$ HARRIS, John, Violence and Responsibility, Londres: Routledge \& Kegan Paul, 1980, p. 60.

${ }^{86}$ Sobre esto vid., por todos, ALCÁCER GUIRAO, "Autonomía, solidaridad y deber de socorro", cit. nota no 1, p. 364 y ss. Por otro lado, la tradicional explicación anglosajona de la marginalidad de la incriminación de las omisiones es probablemente la mejor seña de esta postura. Sobre esto PIÑA ROCHEFORT, La estructura de la teoría del delito en el ámbito jurídico del Common Law, cit. nota $n^{\circ}$ 64, § 6. ASHWORTH, Positive obligations in criminal law, cit. nota $\mathrm{n}^{\circ} 3$, p. 31 y ss. Como hemos visto, incluso desde la perspectiva de los liberales clásicos una afirmación de matices de esta falta de legitimidad, es desafiable.
} 


\section{PIÑA, Juan Ignacio, "La solidaridad como fuente de deberes. Elementos para su incardinación en el sistema jurídico penal”.}

Segundo, aceptando su legitimación en la medida que su incriminación se mantenga absolutamente acotada y excepcional. De este modo, precisamente por su difícil incardinamiento en el paradigma liberal del Derecho penal, solo es susceptible de legitimidad una expresión muy marginal y mínima de estos deberes (incluso subsidiaria) y que solo impongan sacrificios triviales.

A diferencia de lo que sucede con los deberes negativos, los deberes de mejoramiento no tienen en sí mismos una forma de limitación. De este modo, los deberes negativos, entendidos como prohibición de dañar a otro —más allá de la normatividad de conceptos como "dañar" y "otro"- , resultan de un alcance más sencillo de determinar. En cambio, cuando el eje del deber positivo es el mejoramiento de la posición de otro no se vislumbra ahí una limitación consustancial, pues siempre se le puede mejorar más. Precisamente por ello, el desafío más complejo es poner límites a esos deberes positivos. ${ }^{87}$

Desde esta perspectiva, resulta razonable que a la hora de buscar la configuración jurídica de los deberes positivos, la solución de la cuestión de los límites resulte un verdadero imperativo y que las dificultades que entraña la diferenciación de criterios para ello haya operado como aliciente para su marginalización. La búsqueda de criterios que permitan trazar una frontera respecto de aquellos deberes positivos conminados jurídicamente hará, como veremos, que cobren relevancia fundamental dos mecanismos de limitación (1) la selección de las situaciones que detonan el deber y (2) la trivialidad de los sacrificios exigidos.

De este modo, parece imponerse la idea de que sólo podría aceptarse la legitimidad del deber de realizar un sacrificio mínimo o trivial para evitar daños graves a terceros en aquellos casos en los que no existe un deber prevalente de protegerlos. ${ }^{88}$ Es evidente que, si se utiliza como paradigma del deber positivo general el deber de socorro esto parece perfectamente descriptivo. Resulta absolutamente manifiesta la marginalidad de su incriminación y que no solo exige sacrificios triviales, sino incluso limita marcadamente los bienes que deben estar en riesgo. Adicionalmente, la sanción en caso de contravención al deber es absolutamente bagatelaria. La pregunta es si es necesariamente la omisión de socorro la infracción prototípica del deber de solidaridad o si podemos encontrar otras análogas en que ni los sacrificios sean triviales, ni tampoco las sanciones para el caso de contravención. La respuesta no puede si no ser afirmativa y sirva como ejemplo la prestación de un servicio militar obligatorio que sin duda implica sacrificios intensos en la esfera propia de autonomía y sanciones igualmente intensas en caso de incumplimiento del deber. Volveremos sobre esto. ${ }^{89}$

\footnotetext{
${ }^{87}$ BAYÓN, Juan Carlos, "Los deberes positivos generales y la determinación de sus límites: (observaciones al artículos de Ernesto Garzón Valdés)", Doxa, n³ (1986), pp. 35-54, p. 35 y ss.

${ }^{88}$ FISHKIN, James, The limits of Obligation, New Haven: Yale University Press, 1982. Vid también, HODSON, John, The ethics of legal coercion, Dordrecht: Reidal \& Co., 1983, p. 60 y ss.

${ }^{89} \mathrm{Vid}$ Infra 2.2.5.
} 
Polít. crim. Vol. 14, No 27 (Julio 2019), Art. 8, pp. 242-276. [http://politcrim.com/wp-content/uploads/2019/04/Vol14N27A8.pdf]

\subsubsection{Fundamento de los deberes solidarios jurídico-penalmente conminados}

Un ordenamiento social no tiene por qué limitarse a generar personas que no se perturben entre ellas, sino que puede contener el deber de ayudar a otra persona, de edificar con ella, de un modo parcial, un mundo en común.

Jakobs, Omisión: Estado de la Cuestión.

Si bien el fundamento social de la solidaridad parece evidente e históricamente identificable, la fundamentación jurídica de los deberes que de ella emanan no resulta tan pacífica. En otros términos, que la solidaridad haya cumplido una función estructurante en la sociedad y que incluso sea esperada en determinados casos, no parece ofrecer suficientes razones para que la pretensión del Derecho de exigirla sea legítima. Así, la afirmación respecto del carácter pre-institucional de la solidaridad ${ }^{90}$ requiere todavía de la identificación del hito de reconocimiento jurídico, muy especialmente si se aspira a una eventual conminación con una sanción para el caso de contravención. Ya hemos afirmado que el paso desde la comunidad fundada en lo que Durkheim llamó una solidaridad mecánica o natural a una sociedad en que los vínculos se sostienen a pesar (¡o a partir!) de la diferencia, hace surgir lo que hoy entendemos como solidaridad como una propiedad emergente. Esa propiedad emergente, que es uno de los pilares sobre la que descansa el sostenimiento del grupo, no presenta problemas de legitimidad para efectos de su exigencia jurídica. Puesto en términos simples, una sociedad que tiene la solidaridad como uno de sus elementos estructurantes puede exigirla compulsivamente sin que pueda cuestionarse la legitimidad de tal decisión.

En lo concreto, la forma con que se dota al Estado y las atribuciones que se le entregan implican de suyo una distribución de los ejercicios concretos de solidaridad que corresponderán a éste y aquellos que corresponden a los ciudadanos. Es evidente que la propia conformación del Estado ya implica reconocer la imposibilidad de que la estructura social descanse en la mera solidaridad de los miembros y que tal función corresponderá fundamentalmente al Estado, pero entender por ello que ya no hay cabida a la existencia o exigibilidad de episodios especiales o generales de solidaridad entre los ciudadanos es una falacia: non sequitur. PAWLIK ha visto en estos deberes una delegación estatal, es decir, una delegación del Estado que impone sobre los hombros de los ciudadanos el deber de auxiliar a otros. ${ }^{91} \mathrm{Si}$ bien no es particularmente frecuente, agencias de este tipo efectivamente son impuestas a los particulares en algunas ocasiones (agency processes) como el deber de prevenir delitos que se impone a las personas jurídicas en ciertos casos o

\footnotetext{
${ }^{90}$ Sobre esto vid VALENZUELA, "La narrativa del deber de ayudar a otro", cit. nota n ${ }^{\circ} 1$, p. 568.

${ }^{91}$ PAWLIK, Michael, Der rechtfertigende Notstand, Zugleich ein Beitrag zum Problem strafrechtlicher Solidaritätspflichten, Berlin: De Gruyter, 2002. A diferencia de las argumentaciones vinculadas a una supuesta propiedad común originaria, que revive en el caso de la situación de necesidad propuesta por Santo Tomás de Aquino y por Grocio, la idea de que la obligación de ayuda recíproca puede ser establecida a través del derecho positivo por la autoridad aparece en PUFENDORF, Samuel, De Iure naturae et Gentium (2a ed., 1684) Cap. VI, §2. Vid. RENZIKOWSKI, “Solidarität in Notsituationen”, cit. nota n 9, p. 23 y ss.
} 
incluso el deber de reportar operaciones sospechosas en ciertos ámbitos sectoriales. ${ }^{92} \mathrm{Si}$ bien en estos casos la prestación se realiza en beneficio del Estado y no directamente a otros particulares, es visible que en ocasiones los particulares operan como agentes del Estado. ${ }^{93}$ Luego, el entendimiento de estas instituciones como una delegación estatal en principio parecería tener sentido. Sin embargo, una mirada más detenida fuerza hacer algunas distinciones. En primer lugar, los deberes de solidaridad no son equivalentes a las delegaciones estatales de intervenir para impedir delitos (menos en dichos casos en que hay una cierta injerencia del obligado por la generación de los riesgos). Precisamente una seña fundamental de la solidaridad es la absoluta distancia entre el obligado y la generación del riesgo. Esto permite distinguir también entre diferentes clases de procesos de agencia: el que corresponde a la persona jurídica para evitar delitos está más cerca del neminen laedere (evitar una organización defectuosa propia) - y dista por tanto de ser una verdadera agencia estatal - mientras que los sujetos obligados a reportar operaciones sospechosas no tienen injerencia en la generación del riesgo si no simplemente participan de la actividad donde el riesgo se genera - y por tanto si operan como agencia- Las sanciones que se infligen en el primer caso responden a la infracción de un deber negativo, mientras que en el segundo a un deber positivo solidarístico. Estas últimas infracciones en principio no son suficientes para generar una obligación de denuncia ni menos de evitación y son, por tanto, obligaciones que el Estado impone por su proxemia al hecho — por estar ahí-, de modo que sí puede asumirse tanto su carácter de agencia como su fundamento solidarístico. Desde esta perspectiva, ni todas las delegaciones estatales son solidarísticas, ni resulta posible identificar todos los deberes solidarios con una delegación estatal.

Si los deberes de solidaridad han jugado un papel fundamental en la evolución social manteniendo ciertas estructuras de cohesión, entenderla como una delegación estatal pierde de vista la vicisitud misma de la formación del Estado. Tanto la primera estructuración comunitaria como la propia creación del Estado tienen una evidente orientación solidarística y por ello no deja de ser curioso que el análisis histórico-jurídico se haya centrado tan dogmáticamente en el deber negativo de no dañar como deber originario. La afirmación que sostiene que el primer deber que posibilita la vida social es el de no dañar, pierde de vista que evolutivamente, cuando surgen los primeros deberes, el de ayudar al otro frente a un entorno hostil y cargado de peligro era igual de fundamental —al punto que la propia subsistencia pendía de salvar al otro para mantener un grupo capaz de hacer frente a esa adversidad — que el deber negativo originario.

Del mismo modo, la creación del Estado no tuvo solamente a la vista la necesidad de procesar los conflictos entre los miembros y evitar que se dañaran entre ellos, sino también satisfacer un cúmulo de necesidades de mantención de la comunidad, desde la defensa de su territorio, la redistribución de algunos bienes, la custodia de algunos de los miembros, etc. Esas necesidades, que la comunidad ya no era capaz de satisfacer con sus precarias estructuras, forzó a una nueva organización que tenía como primer deber ser eficaz en su satisfacción.

\footnotetext{
${ }^{92}$ ASHWORTH, Positive obligations in criminal law, cit. nota $\mathrm{n}^{\mathrm{o}} 3$, p. 49 y ss.

${ }^{93}$ Al punto que la discusión acerca de la contraprestación que debería ofrecer el Estado por dicha agencia no ha estado ausente de la de su legitimidad. Sobre esto vid. PIÑA ROCHEFORT, Juan Ignacio, Modelos de prevención de delitos en la empresa, Santiago: Thompson Reuters - Abeledo Perrot, 2012, p. 1 y ss.
} 
Dentro de dichas necesidades estaba, por ejemplo, la protección de los individuos contra ciertos riesgos cuyas capacidades de autocustodia se veían superadas. Como en parte se necesitaba Estado para asegurar esa protección, los ciudadanos realizan una delegación para la formación de esta nueva estructura, restringiendo no sólo algunas de sus libertades sino incluso proveyendo de los recursos necesarios para ello. Pero es evidente también que podían identificarse ciertas hipótesis en que el Estado no llegaría oportunamente a proveer el auxilio y que era necesario retener ese deber en los hombros de otros ciudadanos que estuvieran en la posición conveniente para hacerlo. Luego es razonable suponer que dicha delegación, con miras a la eficacia en la prestación que debía realizarse, no fue absoluta sino que mantuvo algunas hipótesis de cargo de los ciudadanos pues no hacerlo implicaba renunciar a una protección efectiva. Estos son, por ejemplo, los casos del deber de socorro o del deber de tolerancia en el caso del estado de necesidad agresivo.

Usando la analogía contractual, el contrato social, como cualquier contrato, obliga no solo a lo que en él se expresa sino también a todas las cosas que emanan de la naturaleza de la obligación, de modo que tiene una cláusula tácita que pone en los hombros de los ciudadanos estos episodios de custodia: la razón misma de la suscripción del contrato era conseguir esa protección efectiva. Esto resulta muy visible en aquellos casos en que se asiste a situaciones de necesidad. Existen ciertas situaciones de necesidad vital en que opera una especie de suspensión de la delimitación de ámbitos de incumbencia. En palabras de Köhler se suspende provisional y reversiblemente "lo mío" y "lo tuyo", 94 de modo de preservar las condiciones para que dicha distinción pueda seguir teniendo sentido. En otros términos, la suspensión de la distinción es la condición de que ella pueda seguir haciéndose, del mismo modo que la suspensión de los ámbitos de incumbencia en el caso del auxilio, es condición de que puedan subsistir ámbitos de incumbencia por la subsistencia de los ciudadanos. ${ }^{95}$ Desde un modelo contractualista esto cobra pleno sentido pues la interpretación de buena fe del contrato social sostendría que en esas situaciones extremas la cláusula incorporada razonablemente rezaría "auxíliense" y no "en tales casos dejadlos perecer". 96 Como hacía notar Grocio, ningún ser humano renunciaría en un contrato recíproco sobre la propiedad a una última posibilidad capaz de salvarle la vida. ${ }^{97}$ Desde esta

\footnotetext{
${ }^{94}$ KÖHLER, Michael, Strafrecht AT, Berlín: Springer, 1997, p. 285, con lo que vuelve a aparecer el elemento de vinculación intersubjetiva propia del modelo kantiano del Derecho.

95 Aquí probablemente subyace la verdadera paradoja de la solidaridad, pues si bien por una parte se dispone una internación en la esfera de la autonomía de quien ostenta el deber para garantizar las condiciones necesarias para que siga existiendo esa autonomía, no lo es menos que las cargas que deriven para él deben ser tales que no terminen por ahogar completamente la suya propia. Vid. VAN WEEZEL, "Solidaridad en el tráfico motorizado", cit. nota n², p. 196.

${ }^{96}$ Resuenan aquí las palabras de FICHTE, Johann Gottlieb, "Einige Vorlesungen über die Bestimmung des Gelehrten", en EL MISMO, Ausgewählte Werke: Tomo I, Darmstadt: WBG Wissenschaftliche Buchgesellschaft, 1962, p. 230: "llamo sociedad a la relación de seres razonables entre sí. El concepto de sociedad no es posible sin la condición de que haya realmente seres razonables además de nosotros (...)". EL MISMO, Grundlage des Naturrechts nach Prinzipien der Wissenschaftslehre (1796), Hamburgo: Felix Meiner, 1979, p. 207: "todo aquel que ha suscrito el contrato ciudadano, tiene un derecho absoluto a exigir ayuda”. Vid. JAKOBS, Günther, La imputación penal de la acción y la omisión, Trad. SÁNCHEZ-VERA, Javier, Bogotá: Universidad Externado de Colombia, 1996, p. 22 y ss.

${ }_{97}$ Grocio hace esta afirmación tratando el ejemplo del hurto famélico. RENZIKOWSKI, "Solidarität in Notsituationen", cit. nota $n^{\circ} 9$, p. 20 y ss. ve aquí una condición contractual que deja sin efecto el contrato
} 


\section{PIÑA, Juan Ignacio, "La solidaridad como fuente de deberes. Elementos para su incardinación en el sistema jurídico penal”.}

perspectiva los deberes solidarísticos, sean de auxilio o de tolerancia no son delegaciones estatales, sino más bien son retenciones del deber original de asistencia con miras a la eficacia de las prestaciones que sean necesarias.

2.2.5. Los límites de la obligación solidaria: ¿la trivialidad del sacrificio?

Cada miembro reconoce una lealtad hacia su comunidad, expresada en la disponibilidad de sacrificar ventajas personales para promover los intereses de ésta.

Miller

Hemos mencionado que uno de los mecanismos de limitación de los deberes positivos generales fundados en solidaridad, además de la selección de las situaciones de peligro que los detonan, es la envergadura del sacrificio exigido. De hecho, suele mencionarse como una seña distintiva de la solidaridad la trivialidad de dichos sacrificios. ${ }^{98}$ Precisamente por esto, suele hablarse correlativamente de un sistema de "altruismo mínimo".99

Sin embargo, más allá de la intuición, la pregunta es por qué podría predicarse la trivialidad como seña distintiva de un deber solidario. Es evidente el papel que juega en esto el modelo liberal marginalizador de la solidaridad, ${ }^{100}$ sumado sin duda al entendimiento de la omisión de socorro como el ejemplo paradigmático de estos deberes. Sin embargo, la pregunta sigue siendo por qué ha de asumirse como punto de partida forzoso, el altruismo mínimo. Es evidente que esa trivialidad busca operar como un escudo ante lo difícil que resulta trazar una frontera entre lo obligatorio y lo supererogatorio. En otros términos, como caminamos en un terreno fangoso, en una zona gris, resulta funcional argumentar la trivialidad de lo exigido para el caso que nos equivoquemos. Puesto de otro modo, como no estamos absolutamente seguros de no estar exigiendo jurídica y compulsivamente obligaciones que deberían ser asunto simplemente del sistema moral, podemos argumentar para tranquilidad de los ciudadanos que los sacrificios que se les exigirán serán lo más pequeños posible. Sin embargo, parece claro que una aproximación crítica a estas formulaciones no está obligada a reconocer forzosamente la frontera en ese lugar ni tampoco que revisados los episodios en nuestro ordenamiento dicha frontera siempre se encuentre ahí. La noción misma de la trivialidad es una noción vaga y plástica que ha servido para eludir un principio moral o jurídico que trace el límite. ${ }^{101}$ Y no debería dejar de llamar la atención que sea la trivialidad la que trace fronteras entre lo obligatorio y lo supererogatorio, o lo que es lo mismo, que se pueda pasar de la trivialidad al heroísmo sin solución de continuidad. ${ }^{102}$

social en estos casos de necesidad extrema, pero más parece, como veremos, una cláusula inherente al contrato y no una suspensión de su vigencia.

${ }^{98}$ GARZÓN VALDÉS, "Los deberes positivos generales y su fundamentación”, cit. n 68, p. 23 y ss.; DE LUCAS, "La polémica sobre los deberes de solidaridad", cit. nota $n^{\circ} 50$, p. 17 y ss.

${ }^{99}$ FISHKIN, The limits of obligation, cit. nota $\mathrm{n}^{\circ}$ 88, p. 72. Fue COMTE, Auguste, Sobre el espíritu positivo, Madrid: Alianza, 2000, p. 30, quien acuñó el concepto de "altruismo" para referirse a los sentimientos benévolos y desinteresados que son propios de la naturaleza humana.

${ }^{100}$ Sobre la tensión dialéctica entre la autonomía personal y la solidaridad vid. CAPALDI, Nicholas, "What's wrong with solidarity?", en ORSI, Giuseppe "et al" (eds.), Solidarität, Rechtsphilosophische Hefte IV, Frankfurt a.M.: Springer, 1995, p. 65.

${ }^{101}$ BAYÓN, "Los deberes positivos generales y la determinación de sus límites", cit. nota no 87, p. 46.

102 Ibíd., p. 47. 
Desde una perspectiva utilitarista, es posible también cuestionar la legitimidad de imponer incluso sacrificios triviales, pues la imposición de un deber generalmente distribuido entre muchos resulta ineficiente. De hecho, una distribución indeterminada puede incluso obstaculizar la consecución del fin buscado. Así, cinco personas tratando de reanimar a un tercero probablemente terminen matándolo. La generalización del deber es en principio ineficiente pues hace que todos, indeterminadamente deban intervenir, en lugar de aquellos que son los más indicados y aptos. La coordinación de esfuerzos y la especialización es siempre más adecuada. Precisamente para ello se aporta al diseño y sostenimiento del Estado (que coordina y racionaliza los esfuerzos), pero además retienen para sí el deber en aquellos casos en que esa especialización resulta ineficaz y de facto es más eficaz entregarlo al conciudadano más próximo. ${ }^{103}$ Por lo mismo, la proximidad opera como criterio de determinación de una obligación indeterminada — adscribe el deber concreto de un modo eficaz-, pero no puede fundamentar la existencia de dicho deber.

Más allá de los paradigmas utilizados, y de lo discutible que resulta que la trivialidad del sacrificio sea consustancial a los deberes de solidaridad, la siguiente pregunta es si una descripción de nuestro sistema de deberes positivos permite sostener que los deberes de solidaridad sólo exigen sacrificios triviales. En otros términos, si efectivamente se ha utilizado la trivialidad para trazar la limitación. Y como hemos mencionado, si se afirma como paradigma el deber de socorro, es decir, el deber que se exige al transeúnte de prestar auxilio a un tercero desconocido que se encuentra en peligro cuando puede hacerlo sin detrimentos propios, la trivialidad parece consustancial. Sin embargo, en deberes solidarios no orientados a mejorar a un otro individual sino a la comunidad no parece posible afirmarlo mismo con la misma intensidad. Así, no parece particularmente trivial la obligación que se impone en el marco del servicio militar obligatorio, donde ni las exigencias para acatarlos son triviales, pues implican una considerable modificación del plan de vida de los ciudadanos llamados a cumplir el deber, ni tampoco lo son las sanciones a imponer en caso de incumplimiento de dicho deber. Otro tanto puede ocurrir en el caso de las intervenciones clínicas indispensables sin consentimiento del paciente cuando hay riesgo para la salud pública donde hay una severa internación en la autonomía del ciudadano en razón de la protección a la comunidad. ${ }^{104}$ Sólo estos casos muestran que no

\footnotetext{
${ }^{103}$ DE LUCAS, "La polémica sobre los deberes de solidaridad", cit. nota $n^{\circ} 50$, p. 37. Sin embargo, y aunque no podemos ahondar en esto aquí, el sendero al que conduce esta cuestión es más bien el de las reglas de exclusión de los obligados cuando hay un deber indeterminadamente asignado. Y en general, aún cuando la prudencia pueda exigirlo, si se trata de un deber genuinamente indiferenciado la especialización y la división del trabajo juegan un papel más bien modesto. Si hay cinco bañistas, todos ellos obligados por solidaridad a auxiliar al menor que empieza a ahogarse, resulta relativamente claro que el inicio de la prestación de salvataje por parte de uno de ellos desplaza a los demás fuera de la órbita del deber. Es cierto también que ese desplazamiento es transitorio, pues si aquel que ha iniciado el salvataje deja de prestarlo — con independencia de la responsabilidad de éste que, por asunción y habiendo desplazado esos otros mecanismos de custodia, puede ser incluso sancionado a título de comisión—, la obligación resurge para los presentes. La existencia de sujetos más calificados, pero no obligados institucionalmente, no produce exclusión de los otros próximos, pues ello implicaría que se asignaría un mayor o preferente deber a aquel a que tiene mayores posibilidades de eficacia. Todas estas cuestiones ofrecen importantes desafíos que no podemos enfrentar aquí.

104 Dispone el artículo 3 de la Ley 41/2002 (BOE 274/2002) en su numeral segundo que $2^{\circ}$ que "Los facultativos podrán llevar a cabo las intervenciones clínicas indispensables en favor de la salud del paciente, sin necesidad de contar con su consentimiento, en los siguientes casos: a) Cuando existe riesgo para la salud
} 


\section{PIÑA, Juan Ignacio, "La solidaridad como fuente de deberes. Elementos para su incardinación en el sistema jurídico penal”.}

siempre hemos tenido particulares inconvenientes en consagrar cargas solidarísticas bastante intensas y alejadas de cualquier trivialidad. ${ }^{105}$

Sin embargo, podría argumentarse que en estos casos, se trata de deberes en que la prestación se dirige a la comunidad toda y no a un tercero determinado, pues en tales casos — como en la omisión de socorro o en el deber de tolerancia en la necesidad agresiva—, los sacrificios siempre son triviales. Ello, de cualquier forma, tampoco resulta del todo cierto. En la historia reciente de nuestra legislación es posible encontrar deberes de solidaridad orientados a auxiliar al nasciturus (y no a la colectividad toda) que imponen cargas mucho más que triviales. A modo de ejemplo, ordenamientos que no reconocen la llamada indicación ética para poner término al embarazo en caso de violación, imponen un deber de sostenimiento del embarazo a la madre que en caso alguno podría denominarse trivial y el único fundamento que sustenta el deber es la solidaridad. En dichos casos, en que el nasciturus se encuentra alojado en el seno materno en contra de la voluntad de la gestante (e incluso a pesar de su resistencia) y no existiendo ningún vínculo de carácter institucional el deber de sostener el embarazo al término sólo podía explicarse jurídicamente como un deber de solidaridad que exige un sacrificio de gran intensidad.

De este modo, la afirmación de que los deberes positivos generales sólo pueden exigir sacrificios triviales no solo no es necesaria, sino que puede desafiarse tanto de facto como de lege lata.

\section{Corolario: Persona, Roles especiales y Solidaridad}

Al comenzar estas notas se hizo presente que las estructuras propias de la imputación penal mostraban un sistema que descansa fundamentalmente en la distinción de dos tipos de deberes: la infracción del deber general negativo de no dañar y la infracción de los deberes positivos especiales asociados a una determinada posición. Tampoco puede caber duda que éstos son los que han centrado las preocupaciones de la dogmática penal.

Sin embargo, ya ha quedado claro que coexisten con ellos deberes cuya infracción da origen a una forma de responsabilidad que en principio no parece poder encuadrarse en las formas mencionadas de responsabilidad por la propia organización o de responsabilidad institucional, sino que más bien se refiere a la infracción de deberes de asistencia a terceros con los que el agente no se encuentra especialmente vinculado. A esos deberes hemos denominado deberes positivos generales fundados en la solidaridad.

Puesto de otro modo, la asunción de que existen dos formas de responsabilidad -responsabilidad por organización y responsabilidad institucional—y que la denominada

pública a causa de razones sanitarias establecidas por la Ley. En todo caso, una vez adoptadas las medidas pertinentes, de conformidad con lo establecido en la Ley Orgánica 3/1986, se comunicarán a la autoridad judicial en el plazo máximo de 24 horas siempre que dispongan el internamiento obligatorio de personas". Vid. CAMPOY CERVERA, Ignacio, "Una revisión de la idea de dignidad humana y de los valores de libertad, igualdad y solidaridad en relación con la fundamentación de los derechos", Anuario de Filosofía del Derecho, $\mathrm{n}^{\mathrm{o}} 21$ (2004), pp. 143-166, p.162.

${ }^{105}$ Vid. ASHWORTH, Positive obligations in criminal law, cit. nota $\mathrm{n}^{\mathrm{o}} 3$, p. 56 y ss. respecto de la discusión anglosajona sobre el alcance del deber de los particulares de asistir a la autoridad para evitar delitos. 
responsabilidad por organización descansa exclusivamente en el deber negativo originario de no dañar a otros debe desafiarse. De hecho, puesto en clave de roles, podría coherentemente sostenerse que la principal distinción se traza entre los deberes generales —adscritos al rol persona - y los deberes especiales —adscritos a roles especiales o, lo que es lo mismo, posiciones de garante - y que sobre ella podrían trazarse la distinción adicional entre deberes positivos y deberes negativos. Para ello, hay que asumir que nuestro sistema de responsabilidad ha establecido deberes de solidaridad de carácter general, es decir, con una total desconsideración de la posición específica del infractor. Desde esta perspectiva puede afirmarse desde ya que en nuestro sistema el rol "persona" no se satisface exclusivamente con el deber negativo de no dañar sino que incorpora -si bien de un modo limitado- deberes de auxilio. En otros términos, entender que el único deber que recae sobre todas las personas es el deber negativo de no dañar simplemente no se condice con la forma de nuestro sistema jurídicopenal, sea cual sea la opinión que esto suscite en el observador. De hecho, el reconocimiento mismo de la solidaridad consiste en el desplazamiento de los límites de la incumbencia desde su aparente grado mínimo (individualidad solo constreñida por la obligación de no dañar), extendiéndola hasta formar un ámbito donde también se incluye a los otros, y eso se exige de todas las personas.

Así consagrados estos deberes, probablemente debería reformularse la noción de responsabilidad por organización de modo de incorporar aquellos deberes de solidaridad que tiene sobre sus hombros cualquier "persona". De este modo, el mandato de conducta respecto de la propia organización rezaría: "administre su propio ámbito de organización como le plazca, pero (1) procure que esa organización no sea defectuosa y dañe a terceros y (2) procure modificarla en casos graves cuando puede prestar auxilio sin detrimento propio o incluso con detrimentos de intensidad razonable". ${ }^{106}$ La afirmación de que incluso pueden resultar exigibles detrimentos razonables para cumplir con el deber (y no ninguno o detrimentos mínimos, reconoce que la teoría del "altruismo mínimo" no es capaz de describir todos los casos de solidaridad exigible jurídicamente de que se tiene noticia). Evidentemente debe restar siempre abierta — y aquí pueden albergarse legítimas dudas— la cuestión de si es adecuado que el sistema penal (aunque el quantum de la sanción sea mínimo) deba ocuparse de estas infracciones; pero lo que ha quedado claro es que esa discusión es de carácter político criminal — vinculado al principio de ultima ratio- y no le subyace un problema de legitimidad intrínseco. ${ }^{107}$ Por el contrario, ésta resulta perfectamente legítima de cumplirse con el imperativo de subsidiariedad. Puesto en otros términos, (1) no es de suyo ilegítimo ni consagrar ni conminar penalmente deberes de

\footnotetext{
${ }^{106}$ Citando a Miller, HABERMAS, Jürgen, Facticidad y validez. Sobre el Derecho y el Estado democrático de Derecho en términos de la teoría del discurso, Trad. JIMÉNEZ REDONDO, Manuel, Madrid: Trotta, 1998, p. 632, intenta una explicación en los siguientes términos: La pertenencia a una comunidad política funda deberes especiales tras los que se encierra una identificación patriótica. Este tipo de lealtad va mucho más allá del que cabe a la validez de deberes jurídicos mediados institucionalmente; "cada miembro reconoce una lealtad hacia su comunidad, expresada en la disponibilidad de sacrificar ventajas personales para promover los intereses de la comunidad".

107 VALENZUELA, "La narrativa del deber de ayudar a otro", cit. nota ${ }^{\circ} 1$, p. 568. Y para ello no es necesario incorporar en la sociedad ningún grado de comunidad o comunitarismo, como sostiene PAWLIK, Michael, "Unterlassene Hilfeleistung: Zuständigkeitsbegründung und systematische Struktur", GA, 1995, pp. 360-372, p. 361. Vid. ALCÁCER GUIRAO, “Autonomía, solidaridad y deber de socorro", cit. nota no 1, p. 371.
} 


\section{PIÑA, Juan Ignacio, “La solidaridad como fuente de deberes. Elementos para su incardinación en el sistema jurídico penal”.}

solidaridad (2) la discusión de su legitimidad se refiere a su compatibilidad con el principio de ultima ratio y por ende no es distinto del escrutinio al que debe someterse cualquier incriminación de infracciones al deber negativo de no dañar y (3) la consagración de estas infracciones, en cuanto infracción deberes positivos generales encuentra su posición dentro de la que ha venido en llamarse responsabilidad por organización.

De cualquier modo, la consagración de los deberes de solidaridad también ofrece casos de verdadera solidaridad adscrita a roles. Esto implica que no se trata de consagraciones generales que afecten a toda persona, sino que ciertos individuos, por ocupar determinadas posiciones, tienen obligaciones de auxilio especiales. ${ }^{108} \mathrm{Si}$ bien estos casos generalmente estarán cubiertos por el deber general de solidaridad relativo a la omisión de socorro — con el exiguo tratamiento punitivo que ella entraña—, se ha impuesto específicamente sobre los hombros de algunos un deber de asistencia que, sin perder su carácter solidario, fundamenta una posición de garante y por ende permite atribuir responsabilidad en caso de defraudación.

En definitiva, la solidaridad no es una tercera forma de responsabilidad, diferenciable de la responsabilidad por organización y la responsabilidad institucional. Por el contrario, tanto la responsabilidad por organización como la institucional contemplan una serie de episodios en que es la solidaridad la que fundamenta ese deber, sea con carácter general (exigible a toda persona) o específicamente referida a un rol (exigible a quien lo ostenta). ${ }^{109}$

Esto permite clausurar la taxonomía de nuestro sistema de imputación reconociendo deberes generales positivos (deberes de solidaridad exigibles a cualquier persona), deberes generales negativos (deber de respetar el principio neminem laedere), deberes especiales positivos (deberes de custodia de quien ostenta una posición de garante) y deberes especiales negativos (deber reforzado de no dañar de quien tiene una posición de garante).

\footnotetext{
${ }^{108}$ A modo de ejemplo, así se establece en el Código de Comercio respecto del Capitán de naves marítimas.

109 De otro modo SÁNCHEZ-VERA GÓMEZ-TRELLES, Javier, "Reflexiones acerca del delito de omisión del socorro debido", $C P C$, n 78 (2002), pp. 589-601.
} 


\section{Bibliografía}

AGULNIK, Peter; RIVKIN, Heidi, "Criminal Liability for failure to rescue: a brief survey of french and american law", Touro International Law Review, $\mathrm{n}^{\circ} 8$ (1998) disponible en http://www.agulnicklaw.com/articles/duty.html [visitado el 23/11/18].

ALCÁCER GUIRAO, Rafael, "Autonomía, solidaridad y deber de socorro (Un apunte histórico)", ADPCP LIII (2000), pp. 361-411.

AMENGUAL, Gabriel, "La solidaridad como alternativa. Notas sobre el concepto de solidaridad", RIFP, n¹ (1993), pp.135-151.

ARISTÓTELES, Ética Nicomaquea, Madrid: Gredos, 2000.

ARRIAGADA, Genaro, Los empresarios y la política, Santiago: Lom, 2004.

ASHWORTH, Andrew, Positive obligations in criminal law, Oxford University Press, 2015.

BAYÓN, Juan Carlos, "Los deberes positivos generales y la determinación de sus límites: (observaciones al artículos de Ernesto Garzón Valdés)”, Doxa, n³ (1986), pp. 3554.

BERLIN, Isaiah, John Stuart Mill y los fines de la vida (prólogo a On Liberty), Madrid: Alianza 2007.

BLAIS, Marie-Claude. La solidarité. Histoire d'une Idee, Paris: Gallimard, 2007.

BOUCSEIN, Hildegard, John Stuart Mill und der Idee der Solidarität, Frankfurt a.M.: Fischer, R.G., 1983.

BUSTOS RUBIO, Miguel, "Bien jurídico y sanción penal en el delito de omisión de socorro", Revista de Ciencias Jurídicas y Sociales (FORO, nueva época), n 15 (2) (2012), pp. 157-183.

CADOPPI, Alberto, "Failure to rescue and the continental criminal law", en: MENLOWE, Michael; MCCALL, Alexander (eds.), The duty to rescue. The jurisprudence of aid, Aldershot: Darmouth, 1993.

CAMPOY CERVERA, Ignacio, "Una revisión de la idea de dignidad humana y de los valores de libertad, igualdad y solidaridad en relación con la fundamentación de los derechos", Anuario de Filosofía del Derecho, no 21 (2004), pp. 143-166.

CAPALDI, Nicholas, "What's wrong with solidarity?", en ORSI, Giuseppe "et al" (eds.), Solidarität, Rechtsphilosophische Hefte IV, Frankfurt a.M.: Springer, 1995.

CICERÓN, Sobre los deberes, Madrid: Alianza 2012.

COMTE, Auguste, Sobre el espíritu positivo, Madrid: Alianza, 2000.

COMTE, Auguste, La filosofía positiva, México D.F.: Porrúa, 2003.

DE LUCAS, Javier, "La polémica sobre los deberes de solidaridad. El ejemplo del deber de defensa y su posible concreción en un servicio civil", Revista del Centro de Estudios Constitucionales, $\mathrm{n}^{\circ} 19$ (1994), pp. 9-88.

DUGUIT, León, Traité de Droit Constitutionnel: Tomo III. $3^{a}$ ed., París: De Brocard, 1928.

DURKHEIM, Emile, De la división del trabajo social, Trad. POSADA, Madrid: Akal, 2001.

FERGUSON, Adam, An essay on the history of civil society (1767), Edimburgo: Edinburgh University Press, 1966.

FERNÁNDEZ SEGADO, "La solidaridad como principio constitucional”, Teoría y Realidad Constitucional (UNED), n³0 (2012), pp. 139-181. 
FICHTE, Johann Gottlieb, “Einige Vorlesungen über die Bestimmung des Gelehrten”, en EL MISMO, Ausgewählte Werke: Tomo I, Darmstadt: WBG Wissenschaftliche Buchgesellschaft, 1962.

FICHTE, Johann Gottlieb, Grundlage des Naturrechts nach Prinzipien der Wissenschaftslehre (1796), Hamburgo: Felix Meiner, 1979.

FISHKIN, James, The limits of Obligation, New Haven: Yale University Press, 1982.

GALLO, Ezequiel, "La tradición del orden espontáneo: Adam Ferguson, David Hume y Adam Smith", Revista Libertas, IV (6) (1987), pp. 1-15.

GARZÓN VALDÉS, Ernesto, "Los deberes positivos generales y su fundamentación", Doxa, $\mathrm{n}^{\circ} 3$ (1986), pp. 17-33.

GÓMEZ PAVAJEAU, Carlos Arturo, "La solidaridad en la antigüedad y la dogmática de la omisión”, Derecho Penal y Criminología, vol.26, no 77 (2005), pp.137-226.

GUTIÉRREZ RODRÍGUEZ, Germán, Ética y economía en Adam Smith y Friederich Hayek, México: Universidad Iberoamericana, 2008.

HABERMAS, Jürgen, Facticidad y validez. Sobre el Derecho y el Estado democrático de Derecho en términos de la teoría del discurso, Trad. JIMÉNEZ REDONDO, Manuel, Madrid: Trotta, 1998.

HARRIS, John, Violence and Responsibility, Londres: Routledge \& Kegan Paul, 1980.

HERRERA, Carlos Miguel, "El concepto de solidaridad y sus problemas políticoconstitucionales. Una perspectiva iusfilosófica", Revista de Estudios Sociales, n ${ }^{\circ} 6$ (2013), pp. 63-73.

HODSON, John, The ethics of legal coercion, Dordrecht: Reidal \& Co., 1983.

HOELZL, Michael, "Recognizing the sacrificial victim. The problem of solidarity for critical social theory", Journal for Cultural and Religious theory, 6/1 (2004), pp.4564.

HUME, David, Investigación sobre los principios de la Moral, Trad. LÓPEZ SASTRE, Madrid: Espasa Calpe, 1991.

HUME, David, Tratado de la Naturaleza Humana, Madrid: Tecnos, 2013.

JAKOBS, Günther, La imputación penal de la acción y la omisión, Trad. SÁNCHEZVERA, Javier, Bogotá: Universidad Externado de Colombia, 1996.

JAKOBS, Günther, "La imputación objetiva, especialmente en el ámbito de las instituciones jurídico-penales del riesgo permitido, la prohibición de regreso y el principio de confianza", en su Estudios de Derecho Penal, Trad. Cancio, Manuel "et al', Madrid: Civitas, 1997.

KANT, Immanuel, Fundamentación para una metafísica de las costumbres, Trad. GARCÍA MORENTE, Manuel, San Juan: Pedro M. Rosario Barbosa, 2007.

KÖHLER, Michael, Strafrecht AT, Berlín: Springer, 1997.

KÖNIG, René, "Die Begriffe Gemeinschaft und Gesellschaft bei Ferdinand Tönnies", Kölner Zeitschrift für Soziologie und Sozialpsychologie 7, n 3 (1955), pp. 348-420.

LLINARES GARCÍA, Mar, "La búsqueda de los principios de organización de la sociedad", Gazeta de Antropología, n¹3 (1997), pp. 1-11.

LOCKE, John, Segundo Tratado del Gobierno Civil, Trad. MELLIZO, Madrid: Alianza, 2007.

LUHMANN, Niklas, Ausidfferenzierung des Rechts. Beiträge sur Rechtstheorie und Rechtssoziologie, Frankfurt a.M.: Suhrkamp, 1995.

LUHMANN, Niklas, Confianza, Trad. FLORES, Amada, Barcelona: Antropos, 2005. 
LUHMANN, Niklas, ¿Cómo es posible el orden social?, México D.F.: Herder, 2009.

LUHMANN, Niklas, La moral de la sociedad, Trads. ORTEGA "et al", Madrid: Trotta, 2013.

MAINE, H.J.S., Ancient Law, Its connection with the early History of society and its relation to modern ideas, Londres: John Murray, 1939.

MEAD, Margaret, Sex and temperament in three primitive societies, Nueva York: W. Morrow \& Co, 1935.

MILL, John S., El utilitarismo. Un sistema de la Lógica: Libro VI, Capítulo XII, Trad. GUISÁN, Madrid: Alianza, 2014.

MILL, John S., Sobre la Libertad, Madrid: Edaf, 2014.

MONEREO PÉREZ, Estudio Preliminar a Tönnies, Comunidad y asociación, Granada: Comares, 2009.

MORGAN, Lewis, Ancient society on researches in the lines of human progress from savagery trough barbarism to civilization, Nueva York: H. Holt and Company, 1877.

MORGENSTERN, Henrike, Unterlassene Hilfeleistung, Solidarität und Recht, Frankfurt a.M.: Peter Lang, 1997.

PÁEZ DÍAZ DE LEÓN, Laura (ed.), Vertientes contemporáneas del pensamiento social francés, México: UNAM, 2002.

PAWLIK, Michael, "Unterlassene Hilfeleistung: Zuständigkeitsbegründung und systematische Struktur", GA, 1995, pp. 360-372.

PAWLIK, Michael, Der rechtfertigende Notstand, Zugleich ein Beitrag zum Problem strafrechtlicher Solidaritätspflichten, Berlín: De Gruyter, 2002.

PAWLIK, Michael, Das Unrecht des Bürgers, Grundlinien der Allgemeiner Verbrechenslehre, Tübingen: Mohr Siebeck, 2012.

PECES-BARBA MARTÍNEZ, Gregorio, Curso de Derechos Fundamentales I (Teoría General), Madrid: Eudema, 1991.

PIÑA ROCHEFORT, Juan Ignacio, La estructura de la teoría del delito en el ámbito jurídico del Common Law, Granada: Comares, 2002.

PIÑA ROCHEFORT, Juan Ignacio, Rol social y sistema de imputación, Barcelona: Bosch, 2005.

PIÑA ROCHEFORT, Juan Ignacio, Derecho penal, Fundamentos de la Responsabilidad. $2^{a}$ ed., Santiago: Thompson Reuters, 2014.

PIÑA ROCHEFORT, Juan Ignacio, Modelos de prevención de delitos en la empresa, Santiago: Thompson Reuters - Abeledo Perrot, 2012.

POPPER, Karl, La sociedad abierta y sus enemigos, Trad. LOEDEL, Buenos Aires: Paidos, 1967.

RADCLIFFE, James (Ed.), The good samaritan and the law, Nueva York: Anchor Books, 1966 (reimpr. 1980).

RAGUES I VALLÉS, Ramón, "Proceso al buen samaritano. Acciones de salvamento y responsabilidad por daños", Indret 2/2001 (2001), pp. 1-12 en: http://www.indret.com/pdf/049_es.pdf [visitado el 23/11/18].

RAMOS TORRES, Ramón, "La más melancólica de las reflexiones. Simpatía virtud y fortuna en 'La teoría de los sentimientos morales' de Adam Smith", Política y Sociedad, Vol. 37 (2001), pp. 21-46. 
RAZ, Joseph, The Morality of freedom, Oxford University Press, 1986.

REDFIELD, Robert, The Little community. Peasant Society and Culture, Chicago/Londres: University of Chicago Press, 1960.

RENZIKOWSKI, Joachim, "Solidarität in Notsituationen. ein historischer Überblick von Thomas v. Aquin bis Hegel", en: VON HIRSCH, Andreas, NEUMANN, Ulfrid; SEELMANN, Kurt (Eds.), Solidarität im Strafrecht, Baden Baden: Nomos, 2013.

RITTER, Joachim, Metaphysik und Politik, Studien zu Aristoteles und Hegel, Frankfurt a.M.: Suhrkamp, 1969.

ROBLES PLANAS, Ricardo, "Deberes negativos y positivos en Derecho penal", Indret, 4/2013 (2013), pp. 1-21 en: http://www.indret.com/pdf/1008.pdf [23/11/18].

SÁNCHEZ-VERA GÓMEZ-TRELLES, Javier, "Reflexiones acerca del delito de omisión del socorro debido", $C P C, \mathrm{n}^{\circ} 78$ (2002), pp. 589-601.

SCHOPENHAUER, Arthur, Preisschrift über die Grundlage der Moral, (ed. Hans Ebeling) Hamburgo: Meiner, 1979.

SILVA SÁNCHEZ, Jesús-María, La omisión. Concepto y sistema, Montevideo: B de F, 2003.

SILVA SÁNCHEZ, Jesús-María, "Derechos de necesidad agresiva y deberes del tolerancia", en: VV.AA. Homenaje al Prof. Rodríguez Mourullo, Madrid: Thompson/Civitas, 2005 [disponible también en versión electrónica en: http://www.cervantesvirtual.com/obra/derechos-de-necesidad-agresiva-y-deberesde-tolerancia-0/].

SMITH, Adam, Teoría de los sentimientos morales, Madrid: Alianza, 2013.

SPENCER, Herbert, La ciencia social. Fundamentos de la sociología (3 ${ }^{\mathrm{a}} \mathrm{ed}$.), Madrid: Np, 1886.

TÖNNIES, Ferdinand, Sociología, México: FCE, 1946.

TÖNNIES, Ferdinand, Comunidad y Asociación, Granada: Comares, 2009.

VALENZUELA, Jonatan, "La narrativa del deber de ayudar a otro", Ius et Praxis n 2 (2014), pp. 555-574.

VARONA GÓMEZ, Daniel, Derecho penal y solidaridad. Teoría y práctica del mandato penal de socorro, Madrid: Dykinson, 2005.

VIDAL GIL, Ernesto, "Sobre los derechos de solidaridad del Estado liberal al social y democrático de Derecho", Anuario de filosofía del derecho, n 10 (1993), pp. 89110.

WALDRON, Jeremy, "Who is my neighbour? Humanity and Proximity", The Monist, vol. 86, N³, pp. 333-354.

VAN WEEZEL, Alex, "Solidaridad en el tráfico motorizado. El delito de omisión de auxilio en caso de accidentes", Doctrina y Jurisprudencia penal, ed. Especial (2014), pp. 191-204.

VAN WEEZEL, Alex, "Necesidad justificante y solidaridad", en: CÁRDENAS, Claudia; FERDMAN, Jorge (Coords.), El Derecho penal como teoría y como práctica. Libro en homenaje a Alfredo Etcheberry Orthusteguy, Santiago: Thomson Reuters, 2016, pp. 213-230. 
Polít. crim. Vol. 14, № 27 (Julio 2019), Art. 8, pp. 242-276.

[http://politcrim.com/wp-content/uploads/2019/04/Vol14N27A8.pdf]

WEBER, Max, Conceptos sociológicos fundamentales, Madrid: Alianza, 2006. 